\title{
TABLAS DE NUPCIALIDAD PARA MÉXICO
}

\author{
Julieta QUILODRÁN \\ El Colegio de México
}

\section{INTRODUCCIÓN}

LAS "TABLAS" CONSTITUYEN una de las formas de presentar el comportamiento de la población frente a un determinado fenómeno demográfico en estado puro, o sea, sin interferencia de otros fenómenos demográficos. La distribución por edades del evento estudiado (calendario) y la proporción final de personas a las cuales llega a ocurrirle (intensidad) son dos de las características que se pueden apreciar mediante una tabla. A partir de esta misma distribución de los eventos se pueden calcular medidas de tendencia central como la media, la moda y la mediana que representan índices resúmenes derivados de las tablas.

Al igual que para cualquier otro fenómeno demográfico, se pueden construir tablas de nupcialidad que reflejen la propensión a que este fenómeno ocurre ya se refiera a solteros, viudos o divorciados, expresada en términos longitudinales o del momento. Según sea el conjunto de personas que se tengan en consideración y la forma de medirla, se tendrán en algunos casos tablas de nupcialidad de solteros, viudos o divorciados para uno u otro grupo de generaciones o cohortes, o bien para un momento dado (fecha censal, un año o varios años considerados en conjunto).

La gama de tablas que sugieren las posibilidades antes mencionadas, rara vez pueden ser elaboradas por falta de información adecuada. En realidad, casi siempre se debe recurrir a métodos aproximativos, incluso para dar cuenta de características tan generales como son las que se refieren a la nupcialidad de solteros, la cual afecta, por lo general, a más del $90 \%$ de las personas que sobreviven, por lo menos hasta los 12 o 15 años de edad. Hay países en donde la nupcialidad se inicia en forma más precoz que en otros, de ahí que el límite inferior que se atribuye a este fenómeno varíe entre países.

En el presente trabajo se busca explotar toda la información censal sobre distribución por estado civil y edad existente para México en los censos que se han levantado a partir de 1930. El propósito original era 
reconstruir generaciones a través de la observación en distintos momentos censales, pero la forma de clasificación en grupos de edades muy amplios, como en el caso del censo de 1940, o la inexistencia de una clasificación del estado civil por grupos de edad, como en el caso del censo de 1950, hicieron riesgosa tal empresa. En realidad, con un censo de 1930 que incluía por primera vez la categoría de "unidos" (unión libre) como categoría diferente de la de solteros, cualquier estimación para 1940 y 1950 que utilizara como referencia los datos de 1930 hubiera implicado serios riesgos con respecto a los beneficios de disponer de una tabla de nupcialidad para los hombres y mujeres nacidos entre 1910 y 1924 , época esta última, muy convulsionada por la Revolución como para comparar el comportamiento seguido por las generaciones nacidas durante ella con las posteriores. La Revolución parece haber influido en la intensidad de las uniones de las mujeres pertenecientes a las generaciones nacidas justo después de finalizar la lucha armada. Las generaciones "huecas" correspondientes al periodo revolucionario con cuyos hombres debían unirse las mujeres que nacieron más o menos entre 1918 y 1922 — considerada la diferencia de edades entre los cónyuges - trajo como consecuencia que en estas generaciones la intensidad del matrimonio masculino aumentara y el celibato femenino fuera más abundante. ${ }^{1}$

Al no poder obtener de los datos disponibles una medida adecuada de la nupcialidad desde una óptica longitudinal, se decidió limitar el análisis a la nupcialidad del momento. Para tal efecto se construyeron las tablas de nupcialidad de solteros para 1930, 1960 y 1970 con base en datos censales. Además, se construyó esta misma tabla para 1976 con datos provenientes de la Encuesta Mundial de Fecundidad-México, con el propósito de presentar una estimación lo más actualizada del fenómeno nupcialidad para el conjunto del país.

La información proveniente del censo de 1970 permitió construir, en adición a la tabla de nupcialidad de solteros para el conjunto del país, aquella correspondiente a la población que se declara unida legalmente en el censo. Esta diferenciación entre el comportamiento del conjunto de la población unida, que incluya a la población en unión libre y sólo religiosa, y la población en uniones legales (sólo civil y civil y religiosa), pretende mostrar, aunque sea en forma muy rudimentaria, cómo se diferencia tal comportamiento frente a la nupcialidad según la naturaleza de la unión.

A otro tipo de diferenciación, esta vez espacial, corresponde el juego de tablas que se calculó para cada una de las entidades de la república. Esta parte es la que ha representado el trabajo más extenso, y si se llevó a cabo la construcción de estas tablas fue para mostrar que el país presenta un comportamiento variado en materia de nupcialidad, cuyas repercusiones

1 A. Jourdain y J. Quilodrán, "Análisis de la nupcialidad legal, por generaciones en México, 1922-1969", DEMografía y economía, Vol. VIII, Núm. 2, El Colegio de México, 1970. 
sobre las demás variables demográficas, en especial la fecundidad y la migración, pueden ser también de diversa índole.

El problema mayor del análisis de tipo transversal es que supone que el comportamiento, en este caso frente a la nupcialidad, de los hombres y mujeres pertenecientes a diferentes generaciones que conforman la generación ficticia considerada, representa efectivamente la nupcialidad del momento en que se efectuó la medición. Es decir, supone estacionario el fenómeno nupcialidad a través del tiempo. Esta limitación se atenúa debido a que es posible disponer de tablas para diferentes momentos en el lapso de los últimos 40 años.

\section{Metodología}

El método utilizado consiste en construir una tabla de nupcialidad de primer orden o de solteros a partir de las proporciones de solteros por grupo de edad al momento de cada censo para cada sexo. ${ }^{2}$

Cualquier tabla consta de tres series, la correspondiente a la población que en un momento dado no ha sufrido el evento en estudio, luego la que se refiere a la distribución de los eventos mismos y, por último la que mide la propensión a que ocurra dicho evento. Como se sabe, basta con conocer una de las series para reconstruir las otras dos.

De aquí en adelante se utiliza la siguiente notación:

$$
\begin{aligned}
C_{x} & \text { designa la frecuencia de solteros a la edad exacta } x \\
m(x, x+a) & \text { las uniones o matrimonios que se celebren entre los ani- } \\
& \text { versarios } x \text { y } x+a \\
Y,{ }_{a} n_{x} & \text { la probabilidad de contraer una unión entre el aniversario } \\
& x \text { y } x+a .
\end{aligned}
$$

En nuestro caso, el cálculo de la tabla se inicia con la serie de $C_{x}$, o sea, con la población que aún no se ha unido. Esta serie se calcula a partir de las proporciones de solteros por edad observadas al momento de un censo.

Las hipótesis sobre las cuales descansa la transformación de las proporciones de solteros observados y la serie de solteros de la tabla $\left(\boldsymbol{C}_{x}\right)$, son las siguientes:

a) la de una independencia entre la nupcialidad y la mortalidad de los solteros; o sea, que la probabilidad que tiene una persona de contraer una unión entre dos aniversarios es independiente de la pro-

2 La fundamentación de la utilización de las proporciones de solteros por grupo de edad en un momento dado para la construcción de la tabla de nupcialidad de solteros se encuentra en R. Pressat, L'analyse demographique, París, PUF, 1969, pp. 162-177. 
babilidad que tiene esa misma persona de morir en ese intervalo de tiempo. Inexistencia, por lo tanto, de una mortalidad diferencial entre solteros y unidos;

b) la de que aquellas personas que migran, de no haber migrado se habrían unido de la misma manera que aquellas que se quedaron.

Aún bajo estas dos hipótesis, subsiste el problema de una migración selectiva por estado civil que al favorecer una emigración de solteros haría disminuir, por este hecho, más rápido las proporciones observadas en un lugar dado con la consiguiente sobreestimación de las uniones que se producen. Por el contrario, en el caso de tratarse de una inmigración de solteros el efecto sería el de una subestimación de la proporción de uniones ocurridas.

Los posibles efectos de la migración sobre la nupcialidad serán retomados cuando se presenten las tablas, en especial las tablas por entidad federativa, donde la influencia de los flujos migratorios interestatales pueden afectar los resultados y aumentar la importancia de los sesgos.

Bajo las hipótesis expuestas en los puntos $a$ ) y $b$ ), se pueden hacer equivalentes las proporciones de solteros en las edades exactas $x$ con la serie de solteros de la tabla de nupcialidad. La transformación se ha realizado aquí a través de un ajụste gráfico de las proporciones observadas de solteros. Como las proporciones censales se presentan por grupos quinquenales de edad, sus valores se centran al medio del intervalo de edades. El supuesto de variación lineal de estas proporciones al interior del grupo de edad no es realista. En el caso de la nupcialidad, la variación de una edad a otra puede ser muy importante, sobre todo en las edades iniciales de ingreso a la unión. Por esta última razón, es más recomendable que la estimación se efectúe a través de proporciones por edades individuales, por lo menos hasta los 25 o 30 años.

Para ejemplificar el procedimiento utilizado en la construcción de las tablas se desarrollará el procedimiento seguido para la tabla de solteros y solteras de 1970.

En primer lugar, se procedió al cálculo de las proporciones de solteros por grupos de edad (véase el cuadro 1), que luego fueron expresados en forma gráfica (gráfica 1), para efectuar el ajuste. Una vez realizado éste, se pudo estimar la serie de $C_{x}$ a través de la simple lectura de la proporción que daba el ajuste para cada edad exacta o aniversario $(15,20,25, \ldots$, $50)$. Se recurrió a un ajuste de tipo gráfico que de algún modo suaviza la disminución brusca de un aniversario quinquenal a otro, ${ }^{3}$ para incurrir en menos error que valiéndose del supuesto de una simple variación lineal.

Una vez establecida la serie de solteros de la tabla $\left(C_{x}\right)$, se estimaron los otros parámetros. Se adoptó como edad límite inferior la edad de 12

3 Todas las curvas de ajuste fueron hechas por la misma persona para evitar variaciones mayores. 


\section{Cuadro 1}

MÉxico: Proporciones DE SOLTERos POR SEXo Y GRUPoS DE EDADES QUINQUENALES

(por cada mil habitantes)

\begin{tabular}{lcc}
\hline Grupos de edad & Mujeres & Hotmbres \\
\hline $12-14$ & 985 & 992 \\
$15-19$ & 788 & 947 \\
$20-24$ & 384 & 612 \\
$25-29$ & 173 & 271 \\
$30-34$ & 104 & 139 \\
$35-39$ & 77 & 91 \\
$40-44$ & 72 & 74 \\
$45-49$ & 71 & 64 \\
$50-54$ & 55 & 64 \\
\hline
\end{tabular}

FuENTE: Dirección General de Entadística, IX Censo General de Población, 1970, México, Secretaría de Industria y Comercio.

\section{Gráfica 1}

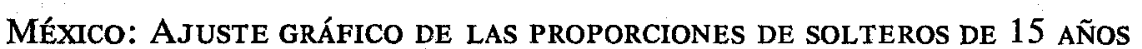
Y MÁs, 1976 (ENCUESTA MUNDIAL DE FECUNDIDAD)

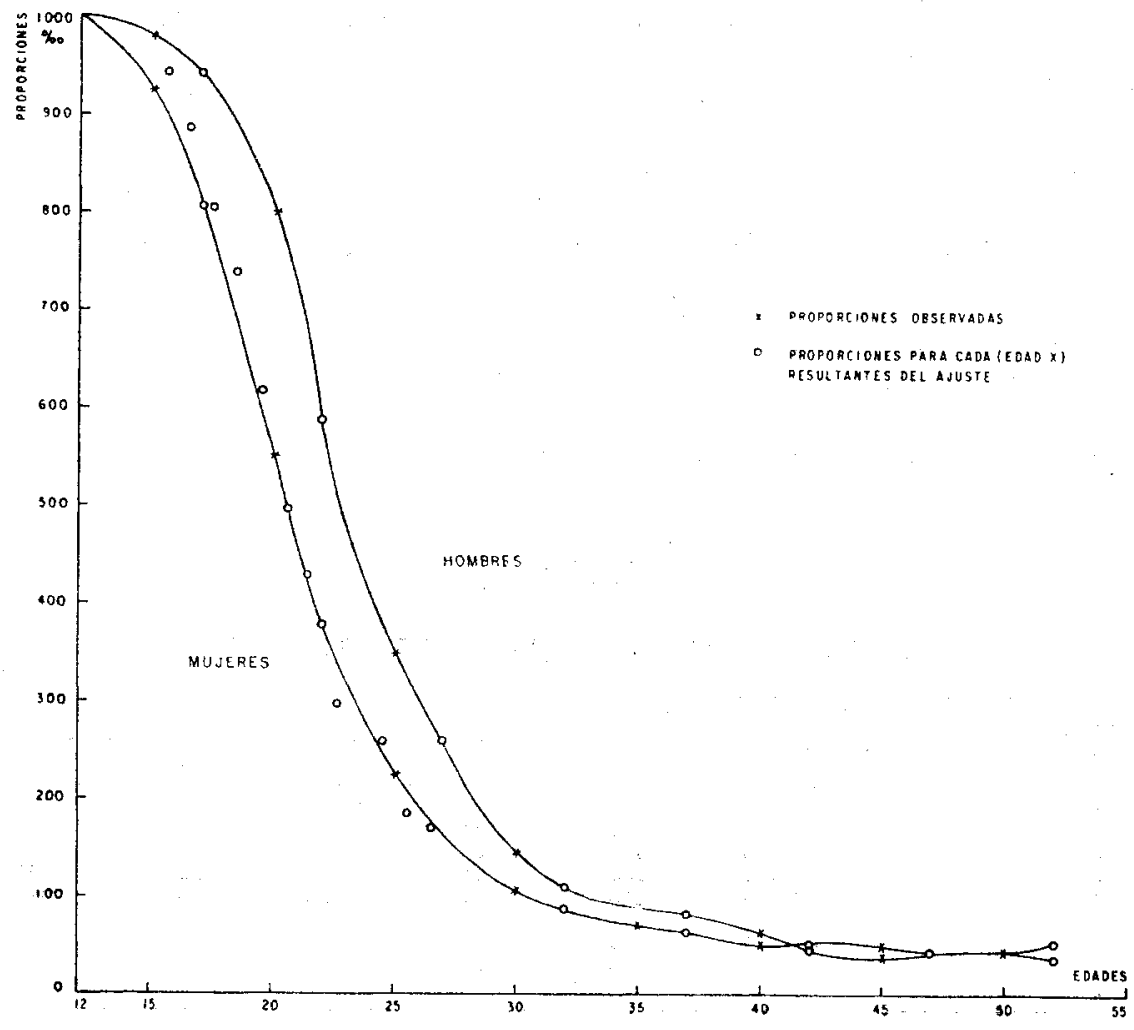




\section{Cuadro 2}

MÉxico: Proporciones de solteros $(C x)$ PARA CADA EDAD EXACTA, 1970

(por cada mil habitantes)

\begin{tabular}{lrr}
\hline $\begin{array}{l}\text { Edad exacta } \\
(X)\end{array}$ & Nujeres & Hombres \\
\hline 12 & 1000 & 1000 \\
15 & 930 & 983 \\
20 & 530 & 835 \\
25 & 250 & 400 \\
30 & 130 & 195 \\
35 & 85 & 110 \\
40 & 75 & 80 \\
45 & 70 & 65 \\
50 & 68 & 60 \\
\hline
\end{tabular}

Fuente: Dirección General de Estadística, IX Censo General de Población, 1970, México, Secretaría de Industria y Comercio.

años y superior la de 50 años para ambos sexos, bajo la consideración de que ni antes de los 12 ni después de los 50 se celebran primeras uniones (véase el cuadro 2).

La serie de matrimonios entre dos aniversarios o edades exactas se obtiene por diferencias entre las proporciones de solteros de dos aniversarios sucesivos:

$$
m(x, x+a)=C_{x}-C_{x}+a
$$

Por su parte, las probabilidades de contraer una unión entre dos aniversarios resulta de la relación siguiente:

$$
{ }_{a} n_{x}=\frac{m(x, x+a)}{C_{x}}
$$

Las tablas así obtenidas figuran en el cuadro 3 .

\section{Cuadro 3}

MÉXICO: TABLAS DE NUPCIALIDAD DE SOLTEROS

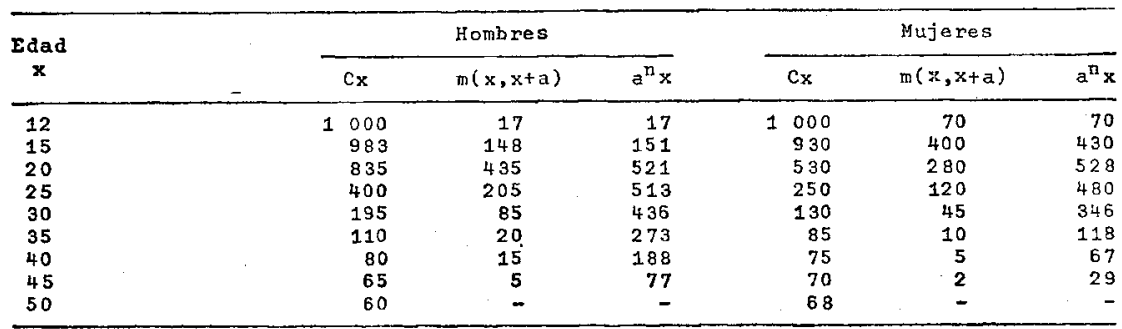


La distribución de las uniones (calendario) muestra que el $47.0 \%$ de las mujeres y el $17.6 \%$ de los hombres del total que llega a contraer al menos una unión se encuentran ya unidos a los 20 años. Este desfase inicial entre los sexos no implica de manera alguna una menor intensidad de la nupcialidad masculina. Según estas mismas tablas, el celibato permanente o definitivo $\left(C_{50}\right)$ es casi $1 \%$ menor entre los hombres que entre las mujeres (6 y $6.8 \%$ respectivamente).

$\mathrm{La}$ intensidad de la nupcialidad ${ }^{4}$ mide la proporción de hombres y $\mathbf{m u}-$ jeres que en una cohorte de 1000 (para cada sexo) llega a contraer una primera unión. Las intensidades varían de una sociedad a otra, de una región a otra, e incluso entre estratos sociales. La universalidad de la unión es más o menos extensa pero nunca alcanza al 100\%. En el caso de México, el $94 \%$ de los hombres y el $93.2 \%$ de las mujeres del total que sobrevive hasta los 12 años llega a contraer al menos una unión.

Por último, las edades medias a la primera unión que se obtienen de estas tablas son de 24.5 años para los hombres y 21.7 años para las mujeres. Esta medida de tendencia central es la característica más importante que se deriva de una tabla de la intensidad que alcanza el fenómeno.

\section{TABLAS DE NUPCIALIDAD}

A partir de la metodología descrita en el inciso anterior, se elaboraron las tablas ya mencionadas para los años $1930,1960,1970$ y 1976 . A excepción de la tabla correspondiente a 1976, las restantes fueron construidas con datos de los censos levantados en esos años. Para 1976 se recurrió, como también se mencionó, a los datos de la Encuesta Mundial de Fecundidad levantada en México ese mismo año.

No se construyó la tabla para 1940 porque la tabulación censal que se hizo de los datos sobre estado civil en función de la edad, se efectuó para grupos de edad tan amplios que la estimación de las proporciones de solteros a los 20 y 25 años, que son decisivos en la fijación del nivel de la edad al unirse, resultaba aventurada.

Para 1950 tampoco se construyó la tabla debido a que para ese censo no se tabuló el estado civil según la edad de las personas. De modo que, sin contar con una buena distribución para 1940 y sin disponer de ninguna para 1950, difícilmente se podía estimar una serie de solteros para 1950 que sirviera para dar cuenta de los cambios que pudiera estar sufriendo la nupcialidad.

En el cuadro 4 se han resumido las características más importantes que se derivan de las tablas construidas cuya versión completa se presenta en el anexo 1.

Si se tiene en cuenta que en 1930 se clasificaron por primera vez las uniones libres y los solteros en categorías distintas, es posible que, si-

4 Intensidada de la nupcialidad $=\left(1-C_{50}\right)$. 
Cuadro 4

MÉXICO: Resumen de las PRINCIPALES CaRACTERÍsticas DE LA NUPCIALIDAD DERIVADAS DE LAS TABLAS PARA $1930,1960,1970$ Y 1976

\begin{tabular}{|c|c|c|c|c|c|c|c|}
\hline \multirow[b]{2}{*}{ Año } & \multicolumn{3}{|c|}{ Hombres } & \multicolumn{3}{|c|}{ Mujeres } & \multirow{2}{*}{$\begin{array}{l}\text { Diferencias } \\
\text { edadä a la } \\
\text { primera } \\
\text { unión }\end{array}$} \\
\hline & $\begin{array}{l}\text { Edad } \\
\text { primerg } \\
\text { uniona }\end{array}$ & $\begin{array}{l}\text { Unidos } \\
\text { a los b/ } \\
20 \text { años }\end{array}$ & $\begin{array}{c}\text { Celibato } \\
\text { definitivo } \\
\left(\frac{q}{0}\right)\end{array}$ & $\begin{array}{c}\text { Edad } \\
\text { prinera } \\
\text { uniónal }\end{array}$ & $\begin{array}{l}\text { Unidos } \\
\text { a los b/ } \\
20 \text { años }\end{array}$ & $\begin{array}{c}\text { Celibato } \\
\text { definitivo } \\
(\%)\end{array}$ & \\
\hline 1930 & 24.8 & 25.9 & 7.5 & 21.5 & 53.4 & 13.0 & 3.3 \\
\hline $\begin{array}{l}1960 \\
1970\end{array}$ & 24.2 & 28.0 & 5.5 & 21.1 & 49.7 & 8.5 & 3.2 \\
\hline $\begin{array}{r}\left.\frac{a}{b}\right)^{c} \\
19 \frac{d}{6} b-\end{array}$ & $\begin{array}{l}24.5 \\
25.1\end{array}$ & $\begin{array}{l}17.6 \\
19.3\end{array}$ & $\begin{array}{r}6.0 \\
25.0\end{array}$ & $\begin{array}{l}21.1 \\
22.1\end{array}$ & $\begin{array}{l}47.0 \\
44.3\end{array}$ & $\begin{array}{r}6.8 \\
23.5\end{array}$ & $\begin{array}{l}3.4 \\
3.0\end{array}$ \\
\hline $\begin{array}{l}\text { a) } \\
\text { b) }\end{array}$ & $\begin{array}{l}24.1 \\
25.0\end{array}$ & $\begin{array}{l}21.2 \\
.17 .8\end{array}$ & $\begin{array}{r}4.5 \\
18.5\end{array}$ & $\begin{array}{l}21.1 \\
22.2\end{array}$ & $\begin{array}{l}47.9 \\
42.9\end{array}$ & $\begin{array}{r}5.0 \\
18.5\end{array}$ & $\begin{array}{l}3.0 \\
2.8\end{array}$ \\
\hline
\end{tabular}

a Edad media.

b Proporción (\%) calculada con respecto al total de uniones concluidas.

c a): Tabla aplicable al conjunto de la población soltera.

b) : Tabla aplicable al total de la población que no ha contraído unión legal.

a Estimación hecha a partir de la información de la Encuesta Mundial de Fecundidad (1976).

guiendo la costumbre anterior, muchas personas en uniones libres fueran registradas como solteras con la consiguiente sobreestimación de las proporciones de solteras. Una sobreestimación de este tipo a su vez acarrea una sobreestimación de la edad media a la primera unión, tanto más grande cuanto más se hubieran concentrado en las edades jóvenes las personas en unión libre que se declararon o fueron registradas como solteras en el censo. Sin embargo, aún en estas circunstancias no se observan cambios fundamentales en la edad al contraer la primera unión entre 1930 y 1976.

Según los datos del cuadro 4 , la edad media al unirse para los hombres sería algo superior a los 24 años y la de las mujeres apenas superior a 21 años. De haberse dado cambios en las generaciones más recientes, éstos no son notorios a nivel de la edad media del conjunto del país. Aunque de otra naturaleza, existen en la población diferencias en las edades al unirse y una primera distinción que puede establecerse es entre la edad media del conjunto y aquella correspondiente a las personas que contraen una unión legal.

Para 1970 y 1976, se construyeron las tablas de nupcialidad aplicables a la población que aún no ha contraído una unión legal, o sea, solteros, en unión libre y matrimonio sólo religioso. ${ }^{5}$ La diferencia media que se

5 Este grupo ha venido disminuyendo con el aumento de la unión legal entre 1930 y 1970 . Con una proporción aproximada de $31 \%$ de solteros a través de los años, el grupo de solteros, convivientes y en matrimonio sólo religioso, ha descendido de alrededor de $60 \%$ en 1930 a $45 \%$ en 1970. Los matrimonios religiosos pasaron del $14 \%$ al $5 \%$ y las uniones libres de $15 \%$ a $9 \%$ en el mismo período. 
obtiene es de un año en casi todos los casos. Esto significa que las uniones legales se celebran a edades más tardías que las uniones libres y los matrimonios sólo religiosos. Esto implica además, que el adelanto en la edad al unirse entre las personas pertenecientes a estas categorías es lo suficiente grande para que la media del conjunto descienda en casi un año, aun cuando el peso relativo de ellas sólo llega al $15 \%$ con respecto al total de la población de 12 años y más. La pauta de edad al casarse es entonces de 25 años para los hombres y de 22 para las mujeres.

Si se consideran las proporciones de unidos antes de los 20 años, ${ }^{6}$ se observa que éstas son mucho más elevadas entre las mujeres que entre los hombres. Aun cuando no existe una tendencia sistemática a la baja, sí se puede advertir que han descendido entre 1930 y 1976. Las proporciones de los hombres unidos antes de los 20 años, de un nivel de $26 \%$ en 1930 pasó a $21 \%$ en 1976 y de un $53 \%$ a un $48 \%$ entre las mujeres. Para ambos sexos las proporciones descendieron 5\%. El hecho de que disminuyan las proporciones de personas que se unen antes de los 20 años no implica un aumento automático de la edad al unirse, porque puede suceder que de manera simultánea se produzca una concentración de la unión en las edades inmediatamente superiores a 20 años.

En la gráfica 2, figuran las distribuciones de las uniones por edad correspondientes a cada una de las tablas, referidas al conjunto de la población que se incluyen en el cuadro 4. Según se puede apreciar en la gráfica correspondiente a los hombres, entre 1930 y 1976 se ha venido produciendo una concentración de las uniones dentro del grupo 20-24 años; han disminuido las proporciones de uniones antes de esas edades, así como también se observa para el mismo período un cierto desplazamiento de las uniones hacia los grupos de edades 25-29 años. Este desplazamiento ocurre $\sin$ que disminuyan las proporciones de mujeres que se unen antes de los 20 años, pero sí de aquellas que lo hacen después de los 30 años. Entre las mujeres podría llegar a darse el mismo fenómeno que entre los hombres, es decir, una concentración de las uniones a edades un poco más tardías que en la actualidad, pero sin una variación de la edad media observada.

En cuanto a la intensidad del celibato, dado por la proporción de personas que permanecen solteras a los 50 años de edad, se observa que esta intensidad es mayor entre las mujeres. Dicho en otros términos, la proporción de hombres que llega a contraer una primera unión es más elevada que la proporción de mujeres (intensidad de la unión). La evolución que marcan los datos confirma una disminución del celibato tanto entre hombres como entre mujeres.

En 1930 la proporción de mujeres célibes fue de $13 \%$, cifra sin duda sobreestimada debido al problema ya mencionado de las categorías de

- Estas proporciones fueron calculadas con respecto al total de unidos a los 50 años, por lo cual no son iguales al de la serie de uniones de las tablas (véase gráfica 2). 


\section{Gráfica 2}

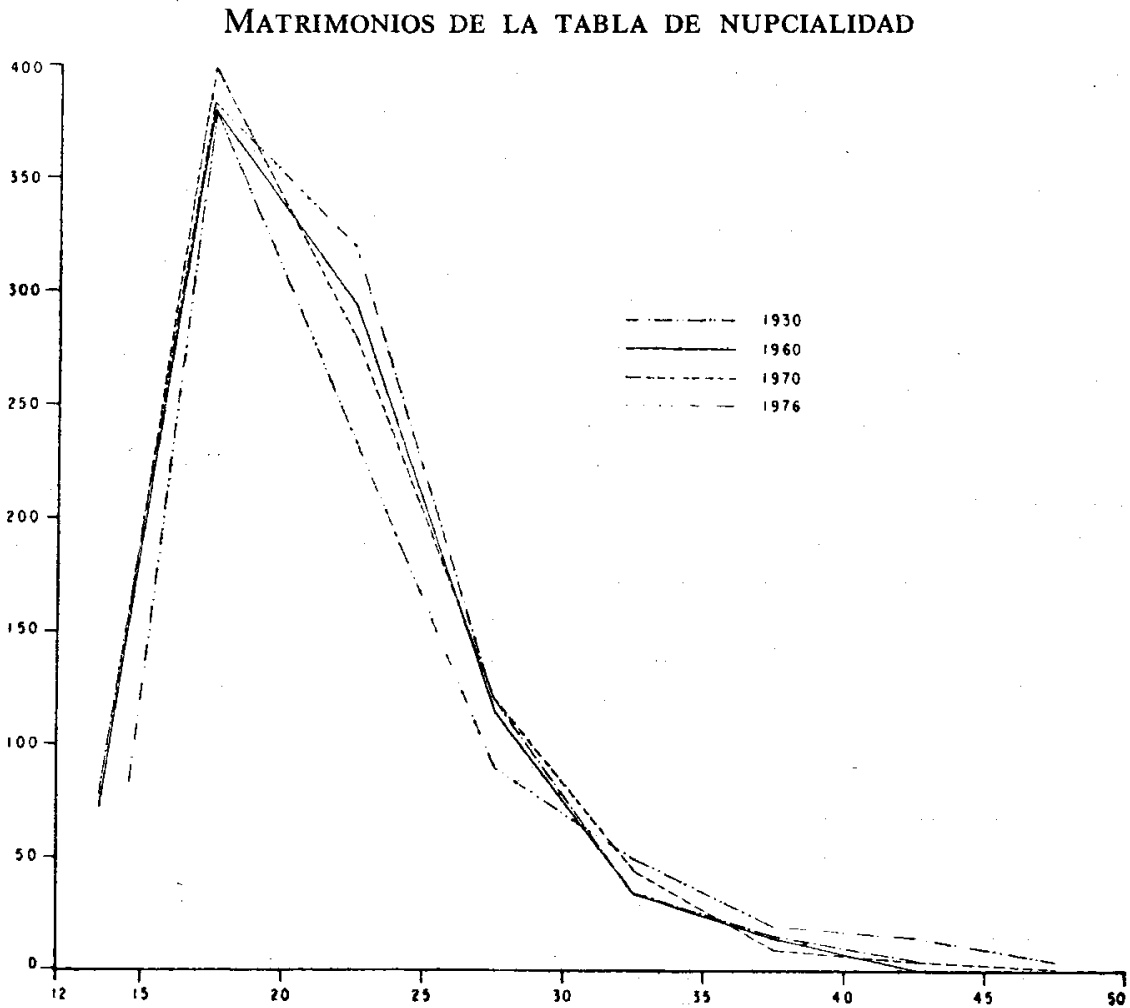

unión libre y solteros. En el caso de las tablas legales para 1970 y 1976, las proporciones de célibes por lógica son más elevadas por el hecho que en ellas no se consideran las uniones libres y los matrimonios sólo religiosos.

Si se adoptan como pautas de la nupcialidad para México, los valores de la edad media a la primera unión y el celibato definitivo correspondiente al conjunto de la población en 1976 , se tiene que:

a) los hombres se unen a una edad media de 24.1 años y las mujeres a los 21.1 años; y

b) que la proporción de célibes a los 50 años es de $4.5 \%$ para los hombres y $5 \%$ para las mujeres.

Para ubicar esta pauta en cuanto a la relación que guarda con las imperantes en otros países se presenta el cuadro 5 . En él se han incluido estimaciones de la edad media a la primera unión y del celibato permanente 
en algunos países de América Latina, África, Asia y Europa. No siempre se obtuvo información para ambos sexos.

De la comparación de los datos mexicanos con los de los países considerados en el cuadro 5, se observa que en México las uniones se celebran a edades relativamente tempranas y que la proporción de célibes permanentes es bastante reducida. Las edades medias al unirse entre los hombres fluctúan entre los 24 y 29 años, siendo las más jóvenes las correspondientes a Argelia y México. El rango de variación de esta característica entre países es mucho más amplio entre los hombres que entre las mujeres. Así, mientras las diferencias entre los hombres son de aproximadamente 4 años, entre las mujeres son del orden de 2.5. Se ha dejado fuera de esta estimación a Irlanda por presentar características muy diferentes al resto de los países, como también a Japón por el hecho de que se cuenta con la edad mediana y no la media.

\section{Cuadro 5}

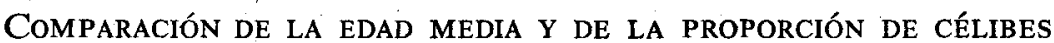
DE MÉXico CON LOS DE OTROS PAÍSES

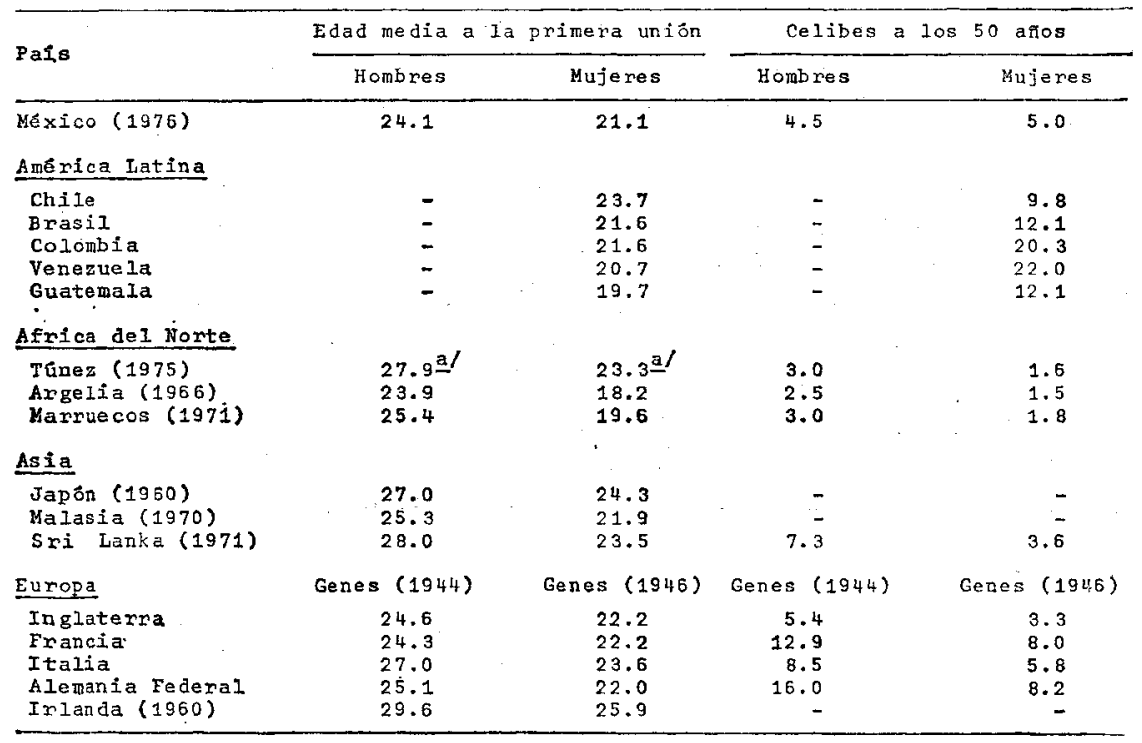

Fuentes: Para Méxcio: Encuesta Mundial de Fecundidad, 1976; para América Latina, "La nupcialidad de las mujeres solteras en América Latina", CELADE, Costa Rica, 1977, p. 37 y 42. Generaciones 1930-1940; para Túnez: Duza y Baldwin, Nuptiality and Population Policy, Nueva York, The Population Council, 1977; para Argelia y Marruecos: D. Tabotin, "Tables de nuptialité africaines", Algérie, 1973; para Japón e Irlanda, L. Rousell, "Le mariage dans la societé française", París, P.U.F., 1975; para Malasia y Sri Lanka, Duza y Baldwin, op. cit., pp. 62-63; para Europa, excepto Irlanda, F. Muñoz-Pérez, "L'evolution récente des premiers mariages dans quelques pays européens", Population, Núm. 3, 1979, pp, 665-675.

a Edad mediana. 
Además de las variaciones de las edades al unirse entre países e incluso entre países pertenecientes a un mismo continente, se observan también fuertes variaciones en la diferencia de edades entre cónyuges. Estas diferencias fluctúan entre un mínimo de 2.1 años en Francia y 5.8 años en Marruecos. México se sitúa, en este aspecto, más próximo a las pautas europeas que a las asiáticas o africanas, donde las diferencias son bastante más acusadas.

A pesar de su concentración en edades próximas a los 21 o 22 años, se está lejos de una uniformidad en lo que se refiere a la edad media al contraer la primera unión en América Latina. Por ejemplo, las diferencias medias entre Chile y Guatemala son de 4 años y lo mismo sucede en los países de África del Norte. En Europa, la tendencia hacia un rejuvenecimiento de la edad a la primera unión ha provocado una cierta homogeneización de ellas. De cualquier manera, la edad al unirse que impera en México lo ubica dentro del grupo de países con una pauta de nupcialidad temprana, aunque no sea éste de los más jóvenes que existen.

En cuanto a los niveles de celibato definitivo, no cabe duda que África presenta los niveles más bajos, lo cual significa que en ese continente es donde el fenómeno nupcialidad es más universal tanto entre hombres como entre mujeres. La situación europea es variada, tal vez por los mismos cambios que están ocurriendo dentro de la nupcialidad. En América Latina (mujeres), los niveles de celibato son sorprendentemente elevados. Cabe aclarar que, en este último caso, las cifras manejadas provienen de estimaciones hechas para el conjunto de la población unida mediante el método de Coale lo cual es posible que responda más a los supuestos de este método que a la situación real. Estas proporciones de célibes se consideran muy elevadas debido a que corresponden a poblaciones todavía con fecundidad alta y edades tempranas a la unión, características que por lo general van asociadas a un reducido celibato permanente.

La proporción de mujeres célibes en México es mucho más reducida que en el resto de América Latina y que en varios países europeos, pero a diferencia de lo que sucede en todos ellos, es algo más elevada que la de los hombres.

\section{TABlas DE NUPCIALIDAD POR ENTIDAdES FEDERATIVAS PARA 1970}

Mediante el mismo método de las proporciones de solteros adoptado para la construcción de las tablas presentadas antes se procedió al cálculo de las tablas del momento para cada una de las entidades federativas.

La información utilizáda corresponde a la distribución por estado civil y grupos de edad de la población de 12 años y más, por sexo y entidades federativas, proveniente del censo de 1970.

Los supuestos de estas tablas son las mismas que se expusieron en la parte metodológica de este trabajo; a saber, las probabilidades de contraer 
una primera unión y morir son independientes así como la de migrar y contraer una primera unión. En este último caso, se supone que el migrante, de haberse quedado en su lugar de origen se habría unido conforme a las mismas pautas que aquellos que no migran.

El problema metodológico más fuerte que surge al construir tablas de nupcialidad por entidad federativa, se deriva del efecto que tienen las migraciones de tipo selectivo por estado civil sobre la forma de cálculo de las tablas. Si se recuerda, la serie de solteros de la tabla que sirve de base a la obtención de las series de uniones y de probabilidades de unirse entre un aniversario de edad $x$ y otro $x+a$, se obtiene a partir de las proporciones de solteros observadas en los diferentes grupos de edades en una población dada. ${ }^{7}$ Esto significa que si se modifican las proporciones de solteros de la población inicial (nativa), por inmigración o emigración, se modifican también las proporciones de unidos que figurarán en la tabla. Esto conduce a su vez, a una sub o sobre estimación de las edades a la primera unión cuyo cálculo se efectúa utilizando como referencia la serie de unidos de dicha tabla.

En caso de una migración (emigración o inmigración), que guarde una estructura por estado civil y edad similar a la de la población de origen o destino, no se produce alteración alguna en las proporciones de solteros observadas en dichas poblaciones. Sin embargo, si se trata de una migración constituida por una proporción mayor de solteros que de unidos, sus efectos van a diferir según se los mida en el lugar de partida o de llegada. Una inmigración con una proporción de solteros más elevada que la que existe en la población nativa tenderá a aumentar las proporciones que se observen en un momento dado. Este aumento será más elevado cuanto más elevada sea la proporción de solteros entre los inmigrantes, comparada ésta con la ya existente en la población de atracción. Por el contrario, estas proporciones tenderán a disminuir en el caso de que los inmigrantes estén compuestos en su mayoría por personas unidas.

千 La fórmula para obtener las proporciones de solteros observados a la edad $x$ al momento del censo en una entidad dada es; $\frac{C x}{P x}$ donde, $C x=$ Solteros observados a la edad $x ;$ y $P x=$ Población total de edad $x$.

a) Cuando se produce una inmigración a la entidad, la fórmula se convierte en

$$
\begin{aligned}
& \frac{C x}{P x+C x^{\prime}+m x^{\prime}}+\frac{C^{\prime} x}{P x+C x^{\prime}+m x^{\prime}} \\
& C x^{\prime}=\text { migrantes solteros de edad } x \\
& m x^{\prime}=\text { migrantes unidos de edad } x .
\end{aligned}
$$

b) Cuando se produce una emigración de la entidad; se convierte en

$$
\frac{C x}{P x-\left(C x^{\prime}+m x^{\prime}\right)}-\frac{C^{\prime} x}{P x+\left(C x^{\prime}+m x^{\prime}\right)}
$$


Los efectos de una emigración preferencial de solteros se traduce, en la población de expulsión, en una disminución de las proporciones de solteros. A la inversa, estas proporciones aumentan cuando la emigración está conformada en su mayoría por personas unidas.

En resumen, se puede decir que la importancia de la interferencia de las migraciones sobre la nupcialidad en las poblaciones de salida o destino, es función del estado civil que predomina entre los migrantes (solteros o unidos) de la edad a la cual se produce la migración y del volumen que ésta alcance. Así por ejemplo, la influencia de una inmigración de personas unidas de edades jóvenes en las cuales todavía la proporción de solteros es muy elevada, en la población que los recibe, hará descender las proporciones de solteros de esta población. Este descenso será mayor entre más grande sea la proporción que representen los migrantes con ,respecto a la población a la cual se añaden.

El efecto de los aumentos y disminuciones de las proporciones de solteros producidos por las migraciones van a traer las siguientes consecuencias sobre las edades medias a la primera unión: $a$ ) en una población de atracción, una inmigración compuesta en su mayoría de solteros tenderá a aumentar la edad media a la primera unión; si la inmigración es de personas unidas el efecto será el de hacer descender esta edad; $b$ ) en una entidad de expulsión, el efecto de una emigración de solteros será el de hacer descender la edad media al contraer la primera unión y a aumentarla si se trata de una emigración de unidos.

La influencia de la migración sobre las proporciones de solteros que se acaba de mencionar, representa un inconveniente en la obtención de las tablas de nupcialidad mediante este método -el de las proporciones de solteros - cuando es aplicado a poblaciones con una gran movilidad espacial para las cuales se desconoce la distribución por estado civil de los migrantes. Sin embargo, la utilidad de estas proporciones no es desdeñable ya que se trata, por una parte, de un tipo de indicador en cuyo cálculo se utilizan datos generalmente disponibles $\mathrm{y}$, por otra, que para sesgar realmente las tendencias de la nupcialidad que se obtienen a través de este método se requiere que el volumen de migrantes sea lo suficiente importante como para que modifique la composición por estado civil de las poblaciones de atracción o de rechazo, sobre todo, en las edades en que suelen celebrarse la mayor parte de las uniones.

En el caso de México, las entidades cuyas edades medias a la primera unión podrían verse más afectadas por la migración serían las que registran proporciones de inmigrantes superiores al $10 \%$ con respecto a su población total. Entre éstas figuran el Estado de México, con 17.2\%; el de Baja California Norte con $16 \%$; y Quintana Roo con $27.9 \%$. En lo que se refiere a los emigrantes, su volumen se distribuye entre un número mayor de entidades, de las cuales sobresalen Zacatecas, Michoacán e Hidalgo, con proporciones de emigrantes sobre su población total de 18, 12 y $9.8 \%$, respectivamente. 
Al sesgo que puedan introducir las migraciones selectivas por estado civil habría que añadir el derivado de una selectividad por sexo, dada la influencia que esto puede tener sobre la descompensación de la población casadera. El desequilibrio del "mercado" matrimonial provocado por migraciones selectivas puede acarrear cambios en las pautas de nupcialidad. Un análisis adecuado del impacto de las migraciones sobre la nupcialidad requeriría de información sobre migración por edad, sexo y estado civil, a nivel internacional y de entidades federativas.

En ausencia de información que reúna todas las características señaladas anteriormente, se recurrirá a la distribución porcentual de los saldos migratorios por entidad federativa, las tasas netas de migración y los índices de masculinidad también por entidad federativa, para aquellas edades de nupcialidad y migración más acusada (véase anexo 3). A falta incluso de datos sobre volúmenes, la única información que sirve para vincular de algún modo la migración internacional con la nupcialidad, es observar los índices de masculinidad de las entidades. Mediante estos índices se puede ver si existe o no un desequilibrio de los efectivos en presencia de cada sexo que pudiera relacionarse con un retardo de la edad al contraer la primera unión. Otro dato disponible que también sirve a este mismo efecto es el relativo a las tasas netas de migración por edad y sexo.

Todos estos indicadores sólo podrán dar cuenta de manera muy aproximada de las posibles interferencias de la migración sobre la nupcialidad. El objetivo de recurrir a ellos no puede ser, por lo tanto, el de corregir las medidas de la nupcialidad obtenidas, sino más bien saber el sentido de los sesgos que pueda provocar la migración (por ejemplo, subestimación o sobreestimación de la edad al contraer la primera unión).

\section{Edad media a la primera unión}

En el cuadro 6 se han incluido las mismas características que se presentaron en el cuadro 4 para las tablas a nivel nacional. En la primera columna referente a hombres y mujeres se hace figurar la edad media al contraer la primera unión para cada entidad federativa.

Una primera revisión de estos datos denota diferencias en las edades al contraer la primera unión entre entidades federativas. En el caso de los hombres, la edad media máxima corresponde al Distrito Federal y Baja California Sur, con 25.6 años, y la mínima a Chiapas con 23.1 años; o sea, fluctuaciones al interior de un intervalo de 2.5 años. Entre las mujeres, la edad media máxima se registra también en el Distrito Federal con 22.5 años y la mínima también para Chiapas con 19.9 años. Quintana Roo alcanza una media incluso algo inferior a Chiapas, pero dada su escasa población y el haber sufrido fuertes inmigraciones en el período 1960-1970, justifican la conveniencia de no considerarla como el límite más bajo de edad al unirse en la República.

Para observar la distribución de la edad media al unirse, se recurrió a representarla en mapas de acuerdo con su reagrupación en cuatro niveles. 
Cuadro 6

México: Resumen de las principales CaRacterísticas de la NuPCialidad POR ENTIDADES FEDERATIVAS, 1970

\begin{tabular}{|c|c|c|c|c|c|c|c|}
\hline \multirow[b]{2}{*}{ Entidad fedarativa } & \multicolumn{3}{|c|}{ Hombres } & \multicolumn{3}{|c|}{ Mujeres } & \multirow{2}{*}{$\begin{array}{l}\text { Difenencias } \\
\text { edadb a la } \\
\text { primera } \\
\text { unión }\end{array}$} \\
\hline & $\begin{array}{c}\text { Edad } \\
\text { prituera } \\
\text { umfónbl }\end{array}$ & 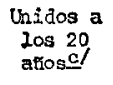 & $\begin{array}{c}\text { Celibato } \\
\text { definitivol } \\
(\%)\end{array}$ & $\begin{array}{c}\text { Edad } \\
\text { primera } \\
\text { uniânibl }\end{array}$ & $\begin{array}{l}\text { Unidos a } \\
\text { los } 20 \\
\text { anos }{ }^{\circ}=\end{array}$ & $\underset{\substack{\text { Celibato } \\
\text { definitivo df }}}{(q)}$ & \\
\hline Aguascalientes & 24.6 & 14.3 & 5.5 & 22.0 & 42.0 & 9.5 & 2.6 \\
\hline Baja California Norte & 25.2 & 11.9 & 7.5 & 21.6 & 43.8 & 7.5 & 3.6 \\
\hline Baja Californía Sur & 25.6 & 7.8 & 10.5 & 21.4 & 47.8 & 8.0 & 4.2 \\
\hline Canpe che & 23.7 & 16.0 & 6.0 & 20.4 & 57.0 & 4.5 & 3.3 \\
\hline $\begin{array}{l}\text { Coohuilia } \\
\text { Colima }\end{array}$ & 24.5 & 14.4 & 6.5 & 21.3 & 50.0 & 6.0 & 3.2 \\
\hline $\begin{array}{l}\text { Colima } \\
\text { chiapas }\end{array}$ & 25.3 & 10.3 & $\begin{array}{r}7.5 \\
5.5\end{array}$ & 21.6 & 46.5 & $\begin{array}{r}7.5 \\
5.5\end{array}$ & 3.7 \\
\hline $\begin{array}{l}\text { Chipas } \\
\text { Chihuałua }\end{array}$ & $\begin{array}{l}23.1 \\
24.7\end{array}$ & $\begin{array}{l}28.6 \\
14.0\end{array}$ & $\begin{array}{l}5.5 \\
7.0\end{array}$ & $\begin{array}{l}19.9 \\
21.3\end{array}$ & $\begin{array}{l}6.4 \\
44.4\end{array}$ & $\begin{array}{l}5.5 \\
6.5\end{array}$ & $\begin{array}{l}1.8 \\
3.4\end{array}-10$ \\
\hline Distrito Federal & 25.6 & 11.2 & 6.5 & 22.5 & 37.6 & 9.5 & 3.1 \\
\hline Purango- & 34.5 & 17.2 & 7.0 & 21.0 & 49.7 & 5.5 & 3.5 \\
\hline Guan aj uato & 24.1 & 19.0 & 5.0 & 21.7 & 43.2 & 7.5 & 2.4 \\
\hline 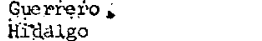 & 23.4 & 19.9 & 4.5 & 20.0 & 62.1 & 5.0 & 3.4 \\
\hline $\begin{array}{l}\text { Hifdalgo } \\
\text { Jalisco }\end{array}$ & $\begin{array}{l}24.2 \\
25.2\end{array}$ & $\begin{array}{l}15.6 \\
7.4 .4\end{array}$ & $\begin{array}{l}7.0 \\
6.5\end{array}$ & $\begin{array}{l}20.4 \\
22.2\end{array}$ & $\begin{array}{l}56.3 \\
40.0\end{array}$ & $\begin{array}{r}6.0 \\
10.0\end{array}-1$ & 3.8 \\
\hline Mérico & 23.9 & $\begin{array}{l}18.9 \\
18.9\end{array}$ & $\begin{array}{l}\begin{array}{l}6.5 \\
5.0\end{array}-10 \\
-1\end{array}$ & 20.7 & $\begin{array}{l}51.3 \\
51.3\end{array}$ & $\begin{array}{r}10.0 \\
4.5\end{array}$ & $\begin{array}{l}3.0 \\
3.2\end{array}$ \\
\hline Miichoacấn & 24.3 & 15.3 & 5.0 & 21.3 & 47.0 & 7.5 & 3.0 \\
\hline Morelos & 24.1 & $1 \% .7$ & 6.5 & 20.9 & 51.9 & 5.5 & 3.2 \\
\hline $\begin{array}{l}\text { Nay arit } \\
\text { Nuevo León }\end{array}$ & 25.2 & 10.9 & 8.0 & 20.9 & 53.2 & 7.0 & 4.3 \\
\hline $\begin{array}{l}\text { Nuevo Leơn } \\
\text { Oexaca }\end{array}$ & $\begin{array}{l}25.2 \\
23.9\end{array}$ & $\begin{array}{l}12.3 \\
31.6\end{array}$ & $\begin{array}{l}6.5 \\
5.0\end{array}$ & 2.2 .1 & 40.0 & 7.5 & 3.1 \\
\hline $\begin{array}{l}\text { Oaxaca } \\
\text { Puebla }\end{array}$ & 23.9 & $\begin{array}{l}21.6 \\
19.6\end{array}$ & $\begin{array}{l}5.0 \\
5.5\end{array}$ & 20.5 & $\begin{array}{l}57.8 \\
52.4\end{array}$ & $\begin{array}{l}6.5 \\
6.5\end{array}$ & 3.4 \\
\hline Quertaro & 24.2 & $\begin{array}{l}19.0 \\
16.2\end{array}$ & $\begin{array}{l}3.5 \\
4.5\end{array}$ & $\begin{array}{l}21.0 \\
21.0\end{array}$ & $\begin{array}{l}52.4 \\
51.1\end{array}$ & $\begin{array}{l}6.5 \\
7.0\end{array}$ & $\begin{array}{l}3.2 \\
3.2\end{array}$ \\
\hline Quintana Roo & $23.2:$ & 24.9 & 5.5 & 19.7 & 64.7 & 2.5 & 3.5 \\
\hline San Luis Potosi & 24.5 & 17.0 & 6.0 & 21.0 & 51.6 & 7.0 & 3.5 \\
\hline $\begin{array}{l}\text { Sinaloa } \\
\text { Sonora }\end{array}$ & 25.1 & 12.0 & 8.0 & 21.6 & 49.2 & 5.5 & 3.5 \\
\hline $\begin{array}{l}\text { Soroora } \\
\text { Tabasco }\end{array}$ & 25.6 & 11.5 & $\begin{array}{l}9.0 \\
4.5\end{array}$ & 22.0 & 40.5 & 6.5 & 3.6 \\
\hline Tamaulipas & $\begin{array}{l}23.8 \\
24.8\end{array}$ & $\begin{array}{l}19.4 \\
13.0\end{array}$ & $\begin{array}{l}4.5 \\
7.5\end{array}$ & $\begin{array}{l}20.0 \\
21.8\end{array}$ & $\begin{array}{l}5.6 \\
43.1\end{array}$ & $\begin{array}{l}3.5 \\
6.0\end{array}$ & $\begin{array}{l}3.8 \\
3.0\end{array}$ \\
\hline TIaxcala & 24.0 & 16.4 & 5.5 & 20.9 & $51.8^{\circ}$ & 4.5 & 3.1 \\
\hline Veracruz & 24.2 & 20.4 & 7.0 & 20.6 & 54.0 & 7.5 & 3.6 \\
\hline Yucatẩn & 23.6 & 23.0 & 6.5 & 21.1 & 50.8 & 5.5 & 2.5 \\
\hline Zacatecas & 24.3 & 19.1 & 5.8 & 21.1 & 49.2 & 6.5 & 3.2 \\
\hline Pais & 24.5 & 17.5 & 6.0 & 21.1 & 47.0 & 6.8 & 3.4 \\
\hline
\end{tabular}

a Características que se derivan de las tablas de nupcialidad de solteros que figuran en el Anexo.

Edad media.

c Proporción (\%) calculada con respecto al total de hombres o mujeres que llegan a contraer al menos una unión.

d A los cincuenta años. 
Si se utiliza como referencia la edad media al unirse en el país, se puede observar que a medida que se avanza de norte a sur, las edades medias disminuyen, a excepción del Distrito Federal. Podría decirse que la frontera entre las pautas de nupcialidad pasa, entre el Pacífico y el Golfo de México, por el norte del estado de Guerrero, Estado de México, Hidalgo y Veracruz. Sin embargo, dentro de estos dos grandes grupos, se pueden distinguir a su vez aquellos que registran las edades más elevadas, entre los cuales destacan, además del Distrito Federal, las Bajas Californias, Sonora, Nuevo León, Jalisco y aquellas con las edades medias más bajas (Chiapas y Quintana Roo).

\section{Mapa 1}

México: EdAd MEdia a LA PRIMERA UNIÓN POR ENTIDADES FEDERATIVAS, 1970. HOMBRES

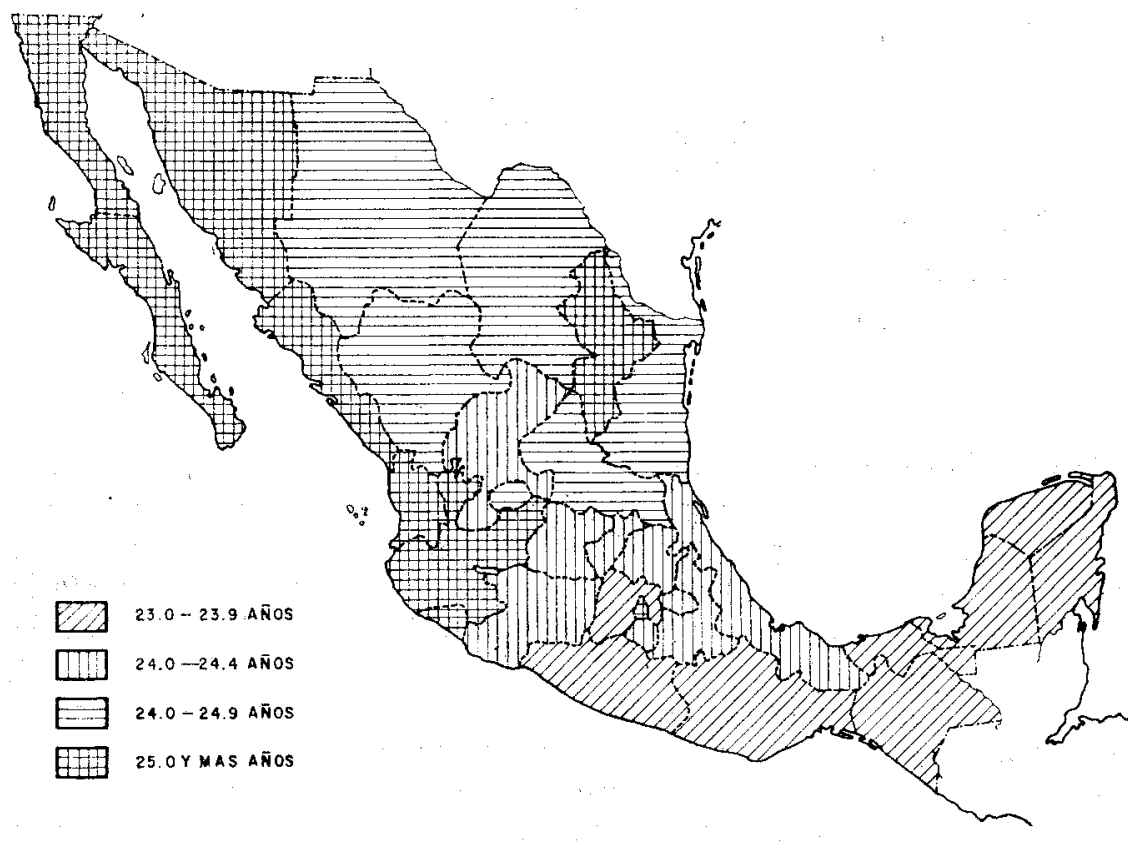

Aun cuando las tendencias que se acaban de marcar son válidas para hombres y mujeres, persisten algunas diferencias entre sexos. Así, en Nayarit, Sinaloa y las Bajas Californias, la edad al contraer la primera unión entre los hombres es comparativamente más elevada que la de las mujeres. En cambio, en Yucatán la edad al unirse es en términos medios relativamente más baja entre los hombres que entre las mujeres.

Para responder aunque sea en forma aproximada a la inquietud formu- 
MÉxico: EdAd MEdia a LA PRIMERA Unión POR ENTIDADES FEderativas, 1970. MUJERES

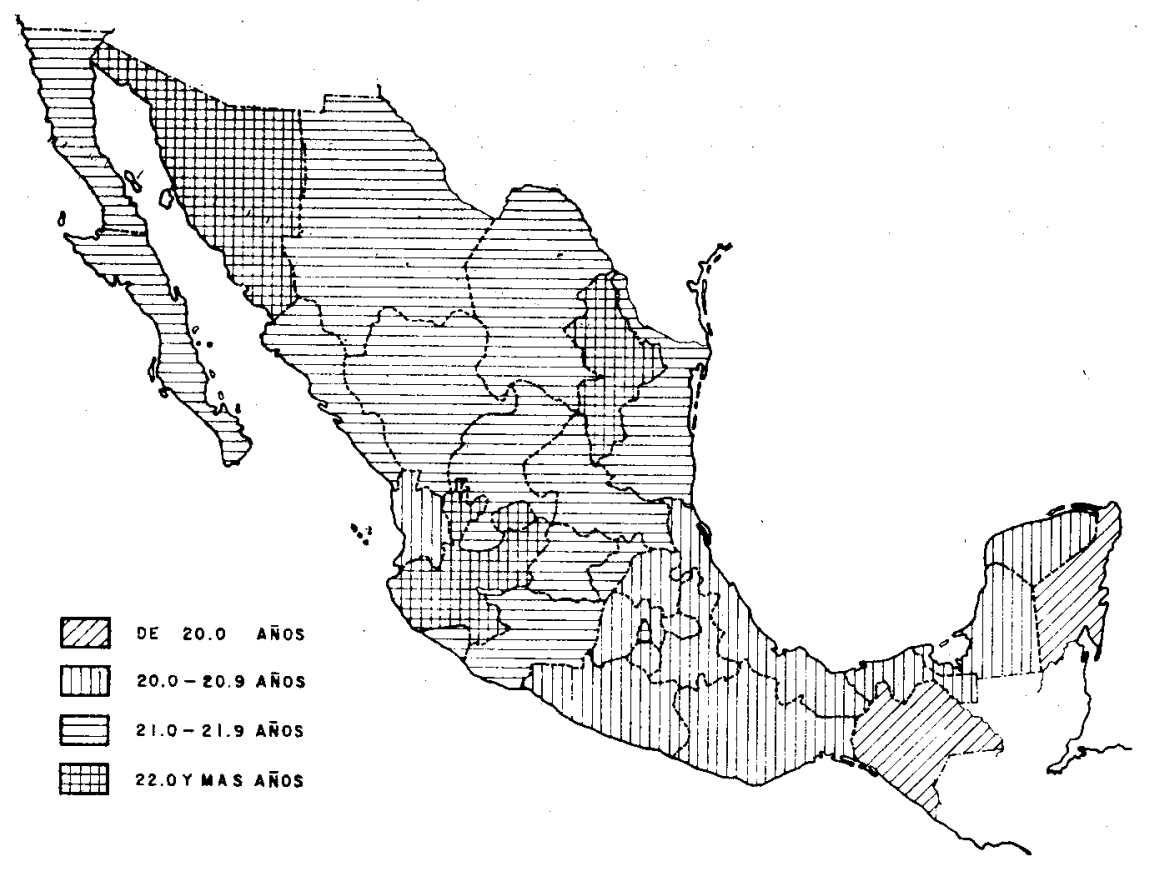

lada antes sobre la posible influencia de la migración sobre la nupcialidad, se procedió a examinar los datos ya mencionados sobre saldos migratorios, tasa neta de migración e índices de masculinidad por entidades federativas. En el anexo 3 se presenta esta información para el período 1960-1970, detallada por sexo, grupos de edad $(15-19,20-24$ y $25-29)$ y entidades federativas. ${ }^{8}$

Si se examinan las edades medias a la unión para 1970 , con respecto a la migración en el decenio inmediatamente anterior a esta fecha, no se observa que las edades medias sean más elevadas o más reducidas en función de si las entidades son de fuerte atracción o de rechazo. Así por ejemplo dos entidades de fuerte atracción como el Distrito Federal y el Estado de México, que atraen por sí solas al $70.6 \%$ de los migrantes del país, presentan características muy diferentes en cuanto a la edad al unirse. En el Distrito Federal se registran las edades más elevadas de todo el país en tanto que en el Estado de México estas mismas son de las más bajas.

8 "Política demográfica regional: Objetivos y metas, 1978-1982", Consejo Nacional de Población, México, 1978, p. 57; y "Tasas de migración neta según grupos de edades por entidad federativa, México, 1930-1970", El Colegio de México (Mimeo). 
En el otro extremo, entre las entidades de mayor rechazo figuran Michoacán, Guanajuato y Zacatecas con el $\mathbf{3 0 . 8 \%}$ del total de emigrantes y que presentan edades medias al unirse ligeramente por encima de la media, así como tasas netas de migración por sexo casi iguales en los grupos de edades 15 a 30 años. Si la emigración (saldos netos migratorios negativos) que registran estas entidades es eminentemente de solteros, dado el método utilizado aquí, la edad media al unirse estaría subestimada. Por el contrario, si la emigración es en su mayoría de personas unidas, el efecto es de una sobreestimación de la edad al unirse, por el hecho que se están sobreestimando las proporciones de personas solteras. Ahora bien, en la entidad o entidades de acogida, el efecto de una inmigración de solteros (saldos netos migratorios positivos) puede acarrear una sobreestimación de la edad al unirse o una subestimación en el caso de que la inmigración sea preferentemente de personas unidas.

En el caso del Distrito Federal y del Estado de México, el examen del impacto de las migraciones debe ser examinado con más detenimiento dado el volumen que éstas representan con respecto al total de su población, en especial tratándose de la segunda entidad.

La importancia relativa de los migrantes al Estado de México $(41.1 \%$ del total de migrantes en el decenio 60-70), da una dimensión distinta al problema de la interferencia entre migración y nupcialidad, sobre todo desde el momento en que parte de ellos son originarios del Distrito Federal. Parece ser que en esta entidad se combina la existencia de una norma a unirse a edad temprana, con dos tipos de inmigración de naturaleza muy diferente, pero que en definitiva lo refuerzan. Por una parte, una inmigración de origen rural cuyos integrantes migraron unidos o se unieron a edades jóvenes siguiendo sus propias pautas de nupcialidad (las pautas rurales), y por otra, una inmigración procedente del Distrito Federal, selectiva en cuanto a estado civil y edad: inmigración de parejas jóvenes. En estas circunstancias, el impacto de la migración de cónyuges en edades jóvenes estaría haciendo disminuir con mayor rapidez las proporciones de solteros observados en esas edades que lo que las haría aumentar la migración de solteros. Por lo tanto, dada la mayor proporción de unidos entre los migrantes, la pauta de edad a la primera unión que resulta de la tabla de nupcialidad obtenida para el Estado de México estaría subestimando dicha edad.

Las tasas netas de migración para esta misma entidad, en edades comprendidas entre 15 y 30 años, muestran un diferencial bastante reducido entre hombres y mujeres. Es decir, no se puede concluir que la población casadera hubiera sufrido desequilibrios como consecuencia de las abundantes migraciones, salvo que se trate de una inmigración de hombres ya unidos y mujeres solteras, en cuyo caso la influencia de la inmigración sería hacia una subestimación de la edad media al unirse de los hombres y una sobreestimación de la edad de las mujeres. Los datos obtenidos 
confirman la existencia de una edad comparativamente más elevada entre las mujeres que entre los hombres, pero con muy poca diferencia.

En el caso del Distrito Federal, a pesar del cuantioso volumen de migrantes que llega a él, la proporción que representa con respecto a la población total no es tan elevada como la de otras entidades (6.9\%). Por esta razón, se considera que la influencia que pudiera tener la migración sobre la nupcialidad no sería decisiva. Si bien la tasa de migración neta en el grupo 15-19 es superior entre las mujeres y de tamaño reducido el índice de masculinidad, en los grupos de edad superiores estos índices se elevan.

Un tercer tipo de indicador utilizado con el afán de estimar el posible impacto de la migración sobre la nupcialidad fue el cálculo de dos clases de índices de masculinidad. Uno obtenido en la forma habitual (efectivos de hombres pertenecientes a un grupo de edad dado sobre los efectivos de mujeres de ese mismo grupo de edad) y otro en el cual se relacionan grupos sucesivos de edad (véase anexo 3 ). La idea subyacente en este segundo caso es la de tener en cuenta de algún modo la diferencia de edades al unirse entre hombres y mujeres, relacionando los hombres de un grupo de edad con las mujeres del grupo de edad inmediatamente inferior. ${ }^{9} \mathrm{Se}$ trata de un indicador muy burdo por cuanto la diferencia de edades al unirse entre hombres y mujeres en México es de aproximadamente 3 años y no de 5 como implica el cálculo realizado, sin contar con el problema que ocasiona el crecimiento de la población al ir aumentando los efectivos de las generaciones más jóvenes.

El examen de los índices de masculinidad "normales" o "habituales", señala como entidades que registran una proporción excesivamente elevada de mujeres (índice de masculinidad de $90 \%$ o menos): en el grupo de edad 15-19 años al Distrito Federal; en el grupo 20-24 años a Baja California Norte, Tamaulipas, Aguascalientes, Chiapas, Guerrero, Oaxaca, Zacatecas y Michoacán. Con índices inferiores a 90\% en el grupo 25-29 años de edad, aparecen Yucatán y Guerrero (esta última entidad es la única que presenta desequilibrio entre los sexos, tanto en el grupo 20-24 como en el 25-29).

Al comparar las tasas de migración neta por sexo correspondientes a las entidades que se acaban de enumerar, se observan diferencias entre ellas en Baja California Norte, Tamaulipas, Aguascalientes, Chiapas, Yucatán, Guerrero y Oaxaca. En Zacatecas y Michoacán, que son las entidades con los saldos migratorios negativos más elevados, las tasas no se diferencian por sexo. Pese a ello, los índices de masculinidad son reducidos en los grupos 20-24 y 25-29 años. Sin embargo, a diferencias similares entre

9 Se calcularon dos índices para cada entidad federativa:

$\begin{array}{lll}\text { Hombres de } & & \begin{array}{l}\text { Hombres de } \\ 20-24\end{array} \\ \text { Mujeres de } & \text { y } & \text { Mujeres de } \\ 15-19 & & 20-24\end{array}$


tasas netas de migración por sexo no siempre se observan repercusiones de la migración sobre los índices de masculinidad (como ejemplo aparecen Estado de México, Tlaxcala y San Luis Potosí).

Tal vez sucede que muchas de las entidades donde existen desequilibrios marcados entre los sexos en las edades entre 20-30 años, a la m1gración interna se está sumando el efecto de una emigración internacional de hombres. Si se consideran los volúmenes de migración interna y su composición por sexo y edad (en las edades de mayor migración, o sea entre 15 y 30 años) se observa que difícilmente ésta puede explicar el nivel de los índices de masculinidad de Baja California Norte, Tamaulipas, Zacatecas y Michoacán, como en cierta medida tampoco los de Guerrero y Aguascalientes.

Según diversos estudios, ${ }^{10}$ los emigrantes a los Estados Unidos provienen de manera principal de los estados de Michoacán, Chihuahua, Guanajuato y Jalisco. De estas cuatro entidades, sólo Michoacán presenta, como acaba de verse, características que sugieren la existencia de flujos migratorios hacia el exterior. O bien, la emigración internacional de las otras tres entidades no es selectiva por sexo, o se trata de emigraciones por períodos lo suficientemente cortos como para que los emigrantes sean declarados como residentes habituales de estos lugares en el momento del censo, ${ }^{11}$ o bien se compensa la emigración internacional con la inmigración interna.

Los estados de Baja California Norte y Tamaulipas presentan saldos migratorios positivos, lo cual significa que se trata de entidades de atracción. De este modo, lo que estaría sucediendo aquí es que las migraciones internas no son suficientes para suplir las emigraciones de hombres a los Estados Unidos que reflejan los índices de masculinidad de estas entidades. En cambio, la situación de Zacatecas y Michoacán sería la de entidades de fuerte rechazo, tanto al interior de la República como hacia el exterior, con la diferencia de que la migración interna no sería selectiva por sexo, pero sí lo sería la internacional (véanse los datos del anexo 3).

El segundo tipo de índice de masculinidad se calculó con el propósito de explicar los desequilibrios en la población que se encuentra en las edades en que las uniones son más frecuentes. Los resultados que se obtienen coinciden en la mayoría de los casos con lo observado a través de los índices de masculinidad ya considerados. Así, las entidades que presentan mayor desequilibrio entre los sexos (menos de 700 hombres por 1000 mujeres) son Baja California Norte, Aguascalientes, Michoacán, Jalisco, Tabasco, Guerrero, Zacatecas y Yucatán.

Tratar de establecer los efectos de la migración sobre la nupcialidad

10 J. Bustamante, "Espaldas mojadas: Materia prima para la expansión del capital nortemericano", Cuadernos del ces, Núm. 9, El Colegio de México, 1975, p. 29.

11 En México los censos son de derecho y entre los residentes habituales de un lugar dado se considera también a aquellos que han estado ausentes por un período inferior a seis meses. 
relacionando índices de masculinidad y edad al contraer la primera unión es difícil y los resultados que se obtienen son escasos. La aproximación entre los indicadores de diversa índole contenidos en el anexo 3 y la edad media al unirse que figura en el cuadro 6, no permite discernir de manera clara en qué entidades la migración interna puede estar afectando a esta característica de la nupcialidad. Existen al respecto dos grandes incógnitas que se refieren a la selectividad de la migración por estado civil y a la migración internacional. Además, habría que analizar los flujos migratorios interestatales y no sólo los saldos migratorios de las entidades, porque pueden producirse compensaciones entre flujos de salida y entrada con migrantes de distintas características.

Como una conclusión de índole general, podría decirse que la migración no parece estar modificando las pautas fundamentales de edad al contraer la primera unión en las diferentes entidades de la República. Las migraciones, según su magnitud y su distribución por edad y estado civil, pueden estar introduciendo alguna ligera sub o sobreestimación, en especial en las entidades de fuerte atracción y rechazo, pero sin llegar al grado de que en una entidad en que priva una edad temprana al unirse ésta se convierta en una edad tardía y viceversa. Como ejemplo se pueden citar los casos de Aguascalientes y Oaxaca que con índices de masculinidad y tasas netas de migración tan desfavorables a las mujeres en una entidad como en otra, la edad media al unirse es elevada en la primera (22.0 años) y reducida en la segunda (20.4 años). Por otra parte, entre las entidades con los índices de masculinidad más elevados, que a veces sobrepasan incluso la unidad (menos mujeres que hombres), se encuentran razones que confirman lo anterior. Las edades media al unirse en entidades tales como Nuevo León o Sinaloa, figuran entre las más elevadas del país, mientras que las de Quintana Roo, con índices de masculinidad también muy elevados, registra las más bajas.

\section{Proporciones de solteros a los 20 y 50 años de edad}

Las proporciones de hombres unidos antes de los 20 años fluctúan entre $7.8 \%$ en Baja California Sur y $28.6 \%$ en Chiapas. Estos extremos coinciden con las edades a la primera unión más elevada y más baja (25.6 y 23.1 años respectivamente). Sin embargo, no se puede establecer una correspondencia total entre una menor proporción de unidos antes de los 20 años y una edad más tardía al unirse; por ejemplo, mientras que en Campeche con una edad media al unirse de 23.7 años se ha unido el $6 \%$ de los hombres antes de los 20 años, en Yucatán, con una edad casi igual 23.6 años, se ha unido una proporción bastante más elevada $(23.0 \%)$.

Esto no significa que haya una ausencia total de relación entre proporción de unidos antes de los 20 años y edad media al unirse. Prueba de esto último es que entre las mujeres las proporciones son mucho más elevadas y sus edades medias a la unión más bajas. Las proporciones de 
mujeres unidas antes de los 20 años fluctúan entre $62.1 \%$ en Guerrero y $37.6 \%$ en el Distrito Federal.

Casi siempre la proporción de mujeres unidas antes de los 20 años es tres veces mayor a la de los hombres unidos hasta esta edad y a veces, como en el caso de Nayarit, llega a ser cinco veces mayor.

El celibato definitivo, aunque es algo más frecuente entre las mujeres que entre los hombres a nivel nacional, a nivel de entidad federativa la situación es variada. En 14 de las 32 entidades federativas, la intensidad es menor entre los hombres, en tres es la misma (Baja California Norte, Colima y Chiapas) y en el resto, la de las mujeres es menor. Las proporciones más elevadas se registran en Baja California Sur para los hombres y en Jalisco para las mujeres (10.5\% y $10 \%$, respectivamente). El celibato definitivo más reducido entre los hombres se presenta en los estados de Guerrero, Querétaro y Tabasco $(4.5 \%)$ y entre las mujeres en Tabasco $(3.5 \%)$ (sin considerar a Quintana Roo por la razón aducida antes).

En general, se observa que en aquellas entidades en donde la edad a la primera unión es más elevada, la proporción de célibes a los 50 años también lo es. En cuanto a las proporciones de unidos antes de los 20 años, también existe una tendencia en éstas a ser más reducidas en aquellas entidades donde la edad al casarse es más elevada.

La diferencia entre la edad media al unirse de hombres y mujeres (última columna del cuadro 6), es de poco más de tres años. Las excepciones, con diferencias menores de tres años, las constituyen los estados de Chiapas (de 1.8), Guanajuato (2.4), Yucatán (2.5) y Aguascalientes (2.6). En el otro extremo, o sea, con diferencias superiores a cuatro años, están Baja California Sur y Nayarit.

Tal como ya se había mencionado, y a modo de resumen, podría decirse que México presenta un comportamiento frente a la nupcialidad donde coexisten pautas de edades muy jóvenes con pautas de edades más - tardías. Aunque la coincidencia no es completa entre los grupos de edades medias a la primera unión entre hombres y mujeres para cada entidad federativa (véanse los mapas 1 y 2), las diferencias no son amplias.

La disminución de las proporciones de personas unidas antes de los 20 años que se ha venido dando a nivel del país, parece indicar que la evolución futura tenderá hacia edades más tardías a la unión. Sin embargo, habría que ir más lejos en el análisis del impacto de las migraciones sobre la nupcialidad; a este respecto, hay que tener en cuenta que la edad media al contraer la primera unión no es más uno de los aspectos que abarca el fenómeno nupcialidad. Estudios que abarquen, por ejemplo, la incidencia de la migración sobre la formación y disolución de uniones serían muy recomendables dada la movilidad que tiene la población del país. 
Gráfica 3

Matrimonios de la tabla DE NUPCIALIDAD

(Hombres)

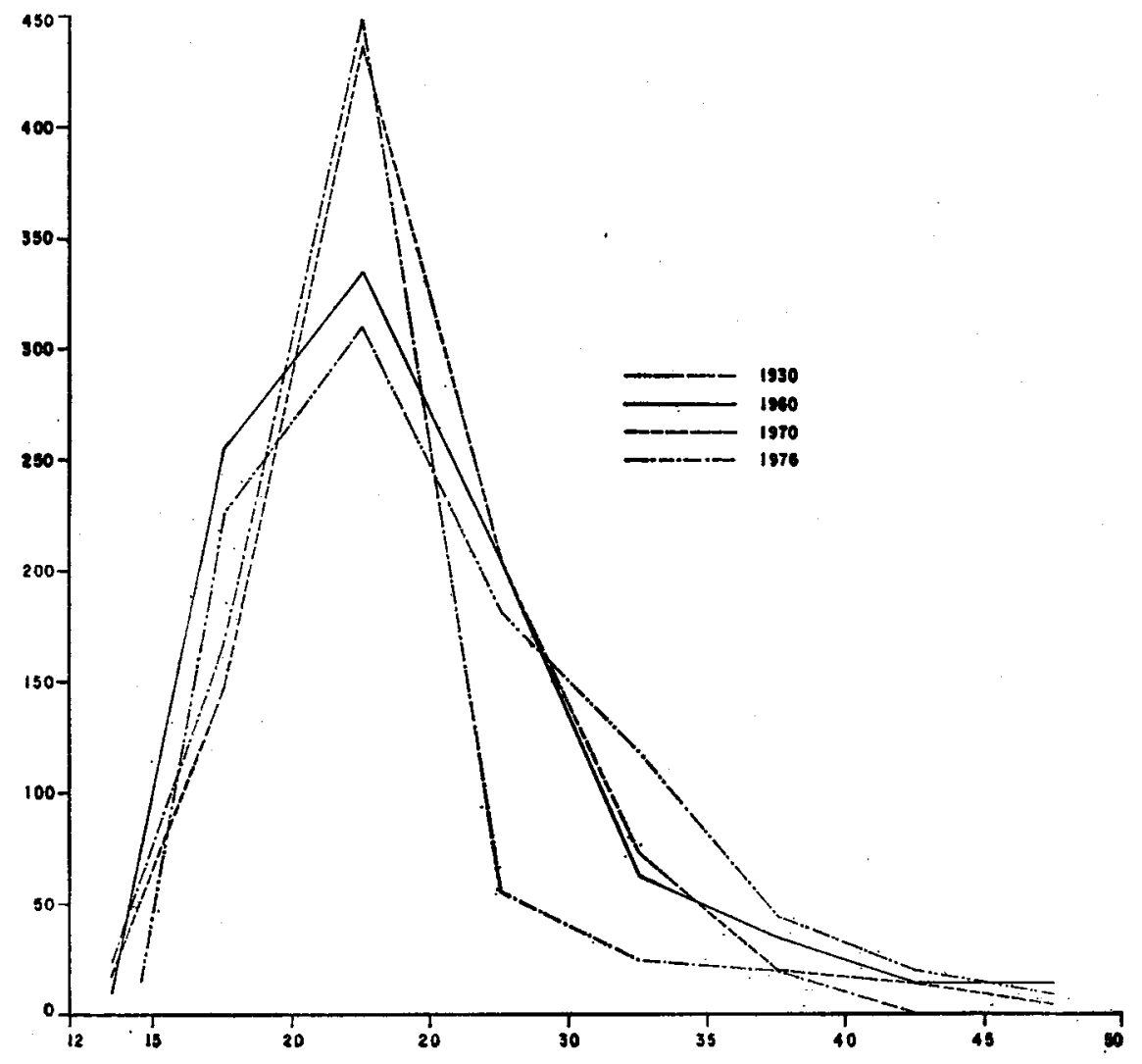




\section{BIBLIOGRAFIA}

v Censo General de Población. 1930, Resumen General, México, Secretaría de la Economía Nacional, 1934.

vi Censo de Población. 1940, Resumen General, México, Secretaría de la Economía Nacional, 1943.

vil Censo General de Población. 1950, Resumen General, México, Secretaría de Economía, 1952.

virr Censo General de Población. 1960, Resumen General, México, Secretaría de Industria y Comercio, 1962.

Ix Censo General de Población. 1970, Resumen General, México, Secretaría de Industria y Comercio, 1972.

Camisa, Z., "La nupcialidad de las mujeres solteras en América Latina", Costa Rica, CELADE, Serie A, Núm. 1034, 1977.

Caravallo, A. L., "Tablas de mortalidad y de nupcialidad de Puerto Rico, 1950 y 1960", Santiago de Chile, CELADE, 1964.

Duza y Baldwin, "Nuptiality and Population Policy", Nueva York, The Population Council, 1977.

Encuesta Mexicana de Fecundidad. Primer Informe Nacional, México, Secretaría de Programación y Presupuesto, Vol. II, 1979.

Goldani Altmann, A. M., "Aspectos formais para o estudio de fecundidade e nupcialidade", São Paulo, 1978 (Mimeo.).

Henry, L., "Démographie: Analyse et modèles", París, Larousse, 1972.

Jourdain A. y J. Quilodrán, "Análisis de la nupcialidad legal por generaciones en México, 1922-1969", DEMOGRAFíA Y ECONOMÍA, Vol. VIII, Núm. 2, 1974.

Merterns, W., "Methodological Aspects of the Construction of Nuptiality Tables", DEMOGRAPHY, Núm. 2, 1965.

Migración Interna en México, 1960-1970. Evolución y Análisis, Serie III, Núm. 5, México, Dirección General de Estadística, 1975.

Muñoz Pérez, F., "L'évolution récente des premiers mariages dans quelques pays européens", POPULATION, Núm. 3, 1979.

Pressat, R., "L’Analyse Démographique", París, 1969.

Quilodrán, J., "Evolución de la nupcialidad en México, 1900-1970", DEMOGRAFÍA Y ECONOMía, Vol. VIII, Núm. 1, 1974.

Roussel, L., "Le mariage dans la societé française", París, PUF, 1975.

Tabutin, D., "Tables de nuptialité africaines", Liège, UIESP, 1973, (Mimeo.).

Tabutin, D. y Vallin, "Manuel d'analyse démographique appliquée à l'Afrique", INSEE, INED, ORSTOM, SEAE (Mimeo.).

"Tasas de migración neta según grupos de edades por entidad federativa, 1930-1970", México, El Colegio de México (Mimeo.).

Vallin, J., "Variations geographique de l'âge moyen au premier mariage des femmes algériennes", Oran, 1973 (Mimeo.). 
Wattelar, Ch. y Wunsch, "Etude démographique de la nuptialité en Belgique", Universidad de Lovaina, 1967.

Wunsch y Termotte, "Introduction to Demographic Analysis", Nueva York Plenum Press', 1978. 
Anexo 1

MÉxico: TABlas dE NUPCIALIDAD DE solteros, 1930

\begin{tabular}{|c|c|c|c|c|c|c|}
\hline \multirow{2}{*}{$\begin{array}{c}E \mathrm{dad} \\
(\mathrm{x})\end{array}$} & \multicolumn{3}{|c|}{ Hombres } & \multicolumn{3}{|c|}{ Mujeres } \\
\hline & $c x$ & $n(x, x+a)$ & $a^{n} x$ & $c x$ & $m(x, x+a)$ & $a^{n} x$ \\
\hline 14 & 1000 & 15 & 15 & 1000 & 82 & 82 \\
\hline 15 & 985 & 225 & 228 & 918 & 282 & 417 \\
\hline 20 & 760 & 310 & 310 & 535 & 235 & 439 \\
\hline 25 & 450 & 182 & 182 & 300 & 90 & 300 \\
\hline 30 & 268 & 118 & 118 & 210 & 50 & 238 \\
\hline 35 & 150 & 45 & 45 & 160 & 20 & 125 \\
\hline 40 & 105 & 20 & 20 & 140 & 15 & 107 \\
\hline 45 & 85 & 10 & 10 & 135 & 5 & 37 \\
\hline 50 & 75 & - & - & 130 & 0 & 0 \\
\hline
\end{tabular}

MÉXICO: Tablas dE NUPCIALIDAd DE SOlteros, 1960

\begin{tabular}{|c|c|c|c|c|c|c|c|}
\hline \multirow{2}{*}{$\begin{array}{c}\text { Edad } \\
(x)\end{array}$} & & \multicolumn{3}{|c|}{ Hombres } & \multicolumn{3}{|c|}{ Mujeres } \\
\hline & & $C_{x}$ & $m(x, x+a)$ & $a^{n} x$ & $c_{x}$ & $m(x, x+a)$ & $a^{n} x$ \\
\hline 14 & & 1000 & 10 & 10 & 1000 & 75 & 75 \\
\hline 15 & & 990 & 255 & 258 & 925 & 380 & 411 \\
\hline 20 & & 735 & 335 & 456 & 545 & 295 & 541 \\
\hline 25 & & 400 & 205 & 513 & 250 & 115 & 460 \\
\hline 30 & & 195 & 75 & 385 & 135 & 35 & 259 \\
\hline 35 & 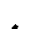 & 120 & 35 & 292 & 100 & 15 & 150 \\
\hline 40 & • & 85 & 15 & 176 & 85 & 0 & 0 \\
\hline 45 & & 70 & 15 & 214 & 85 & 0 & 0 \\
\hline 50 & & 55 & - & - & 85 & - & - \\
\hline
\end{tabular}

MÉxico: Tablas de NuPCialidad (LEGal), 1970

\begin{tabular}{|c|c|c|c|c|c|c|}
\hline \multirow{2}{*}{$\begin{array}{l}\text { Edad } \\
(x)\end{array}$} & \multicolumn{3}{|c|}{ Hombres } & \multicolumn{3}{|c|}{ Mujeres } \\
\hline & $c_{x}$ & $m(x, x+a)$ & $\overline{a^{n} x}$ & $C x$ & $m(x, x+a)$ & $a^{n} x$ \\
\hline 12 & 1000 & 15 & 15 & 1000 & 50 & 50 \\
\hline 15 & 985 & 130 & 132 & 950 & 275 & 289 \\
\hline 20 & 855 & 290 & 339 & 675 & 245 & 363 \\
\hline 25 & 565. & 180 & 319 & 430 & 115 & 267 \\
\hline 30 & 385 & 75 & 195 & 315 & 50 & 159 \\
\hline 35 & 310 & 30 & 97 & 265 & 20 & 75 \\
\hline 40 & 280 & 20 & 71 & 245 & 10 & 41 \\
\hline 45 & 260 & 10 & 38 & 235 & 0 & 0 \\
\hline 50 & 250 & - & - & 235 & - & - \\
\hline
\end{tabular}


MÉxico: Tablas de Nupcialidad de solteros, 1976

\begin{tabular}{|c|c|c|c|c|c|c|c|}
\hline \multirow{2}{*}{$\begin{array}{c}\text { Edad } \\
(x)\end{array}$} & \multirow[b]{2}{*}{$\cdots$} & \multicolumn{3}{|c|}{ Hombres. } & \multicolumn{3}{|c|}{ Nuferes } \\
\hline & & $C_{x}$ & $m(x, x+a)$ & $a^{n_{x}} 0 / 00$ & $c x$ & $m(x, x+a)$ & a. $x \quad 0 / 00$ \\
\hline $\begin{array}{l}12 \\
15 \\
20 \\
25 \\
80 \\
85 \\
40 \\
45 \\
50\end{array}$ & & $\begin{array}{r}1000 \\
990 \\
855 \\
525 \\
315 \\
295 \\
207 \\
195 \\
185\end{array}$ & $\begin{array}{r}10 \\
135 \\
330 \\
210 \\
80 \\
28 \\
12 \\
10 \\
-\end{array}$ & $\begin{array}{r}10 \\
136 \\
386 \\
400 \\
254 \\
119 \\
58 \\
51 \\
-\end{array}$ & $\begin{array}{r}1000 \\
970 \\
650 \\
380 \\
260 \\
215 \\
207 \\
195 \\
185\end{array}$ & $\begin{array}{r}30 \\
320 \\
270 \\
120 \\
45 \\
8 \\
12 \\
10 \\
-\end{array}$ & $\begin{array}{r}30 \\
330 \\
415 \\
316 \\
173 \\
37 \\
58 \\
51 \\
-\end{array}$ \\
\hline
\end{tabular}

\begin{tabular}{|c|c|c|c|c|c|c|}
\hline \multirow{2}{*}{$\begin{array}{c}\text { Edad } \\
(x)\end{array}$} & \multicolumn{3}{|c|}{ Hombres } & \multicolumn{3}{|c|}{ Mujeres } \\
\hline & $c_{x}$ & $m(x ; x+a)$ & $a^{9} \times 0 / 00$ & $c_{x}$ & $\ldots m(x, x+a)$ & $a^{9} \times 0 / 00$ \\
\hline $\begin{array}{l}12 \\
15 \\
20 \\
25 \\
80 \\
35 \\
40 \\
45 \\
50\end{array}$ & $\begin{array}{r}1000 \\
977 \\
798 \\
350 \\
145 \\
145 \\
90 \\
65 \\
65 \\
45 \\
45\end{array}$ & $\begin{array}{r}23 \\
179 \\
448 \\
55 \\
25 \\
20 \\
0 \\
0 \\
0\end{array}$ & $\begin{array}{r}23 \\
183 \\
561 \\
586 \\
379 \\
278 \\
808 \\
0 \\
-\end{array}$ & $\begin{array}{r}1000 \\
925 \\
545 \\
225 \\
105 \\
105 \\
70 \\
55 \\
\\
50 . \\
50\end{array}$ & $\begin{array}{r}75 \\
380 \\
320 \\
120 \\
35 \\
15 \\
5 \\
0 \\
0 .\end{array}$ & $\begin{array}{r}75 \\
411 \\
587 \\
538 \\
383 \\
214 \\
.90 \\
0 \\
-\end{array}$ \\
\hline
\end{tabular}


Gráfica 1

MÉXICO: AJUSTE gRÁfico de LAS PROPORCIONES DE SOLTEROS

DE 14 AÑOS Y MÁS POR GRUPOS QUINQUenales. Censo 1930

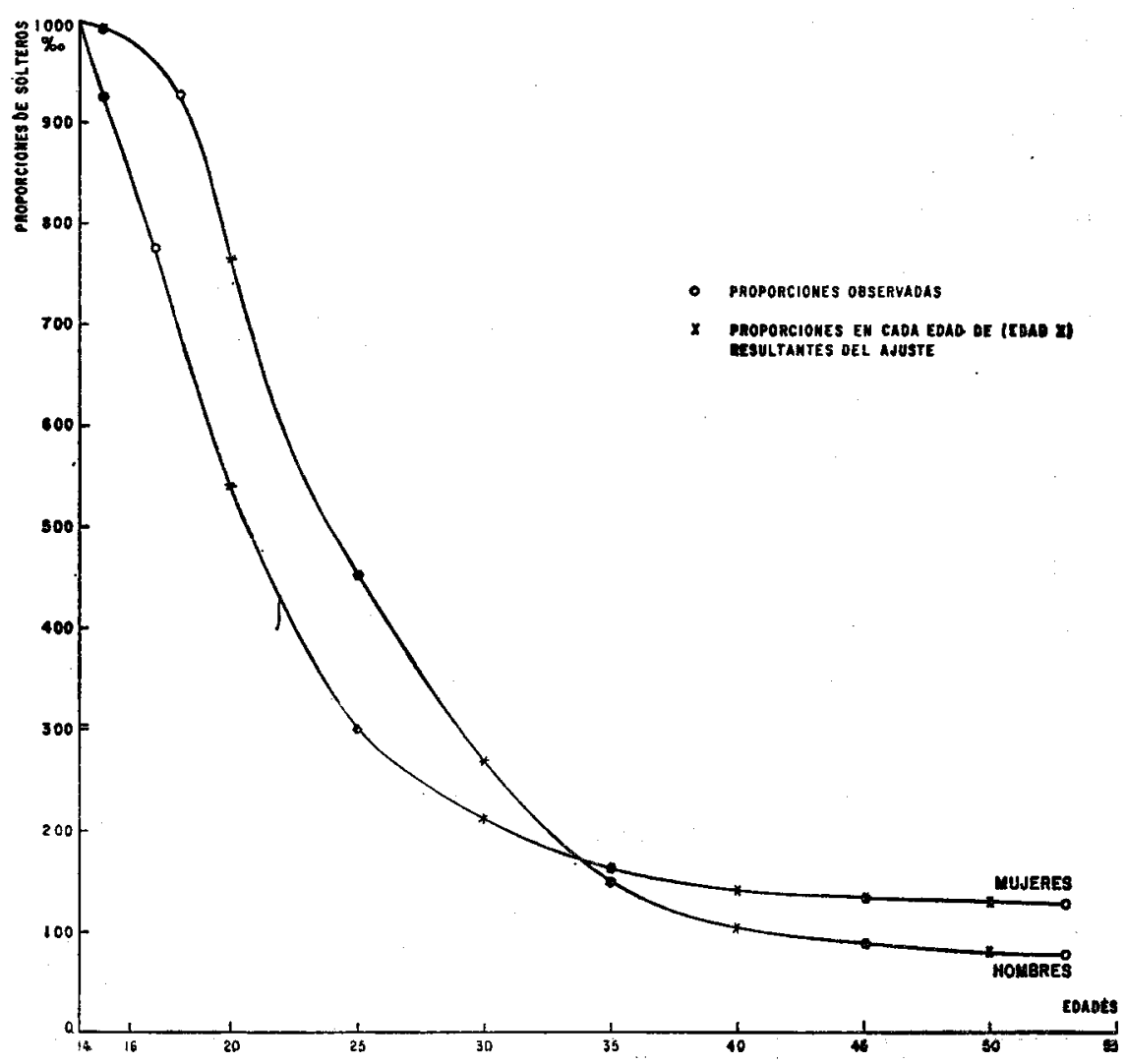


Gráfica 2

México: AJuste gráfico de LAS PRoporciones de 14 aÑos

Y MÁs POR GRUPos Quinquenales DE EDAD. CENSO 1960

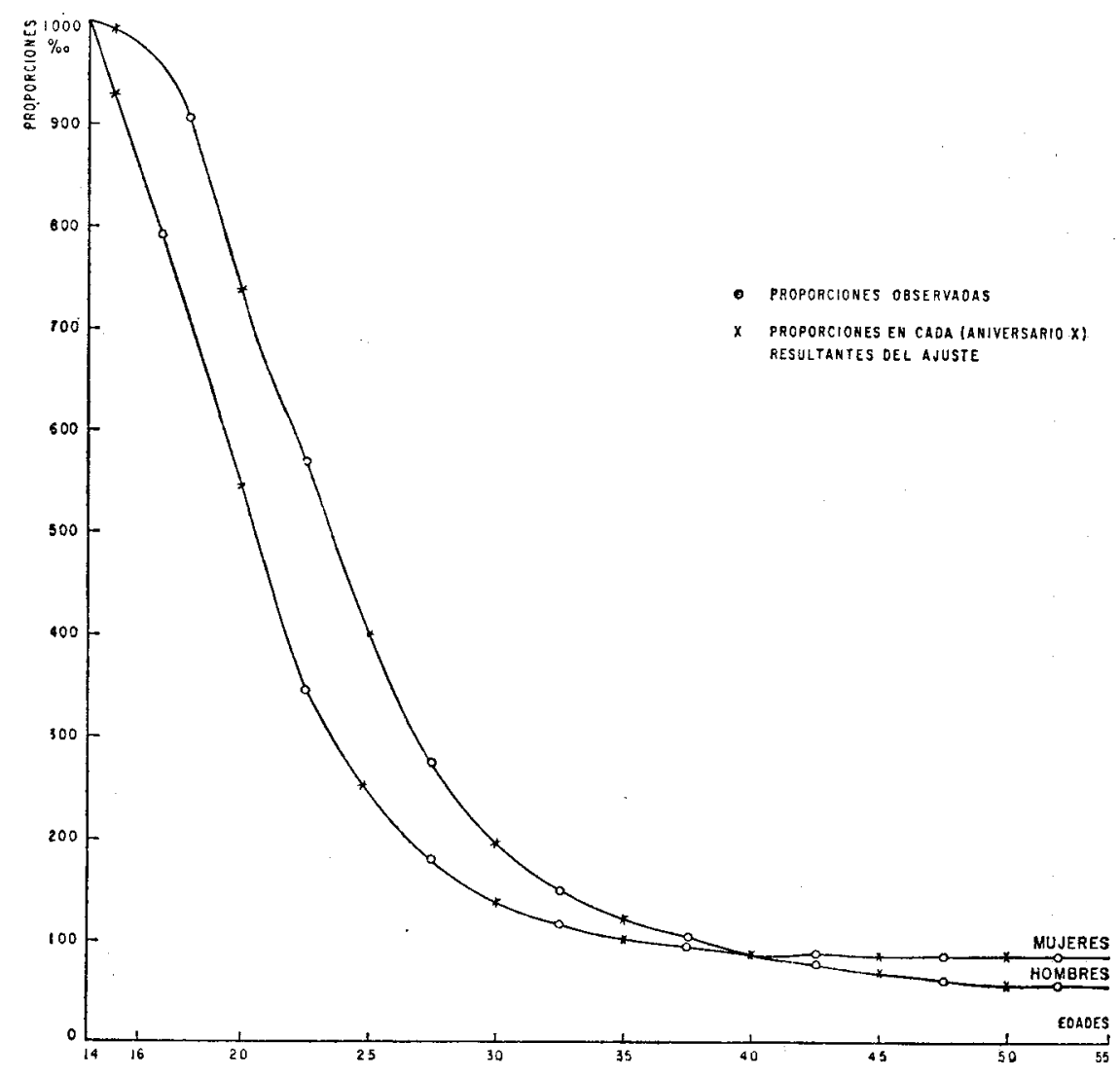


Gráfica 3

MÉxico: AJUSTE GRÁFICo DE LAS PROPORCIONES DE LA POBLACIÓN DE 12 AÑOS Y MÁS (SOLTERA, EN UNIÓN LIBRE Y MATRIMONIO Sólo Religioso) POR GRUPos de edades QUinquenales. Censo 1970

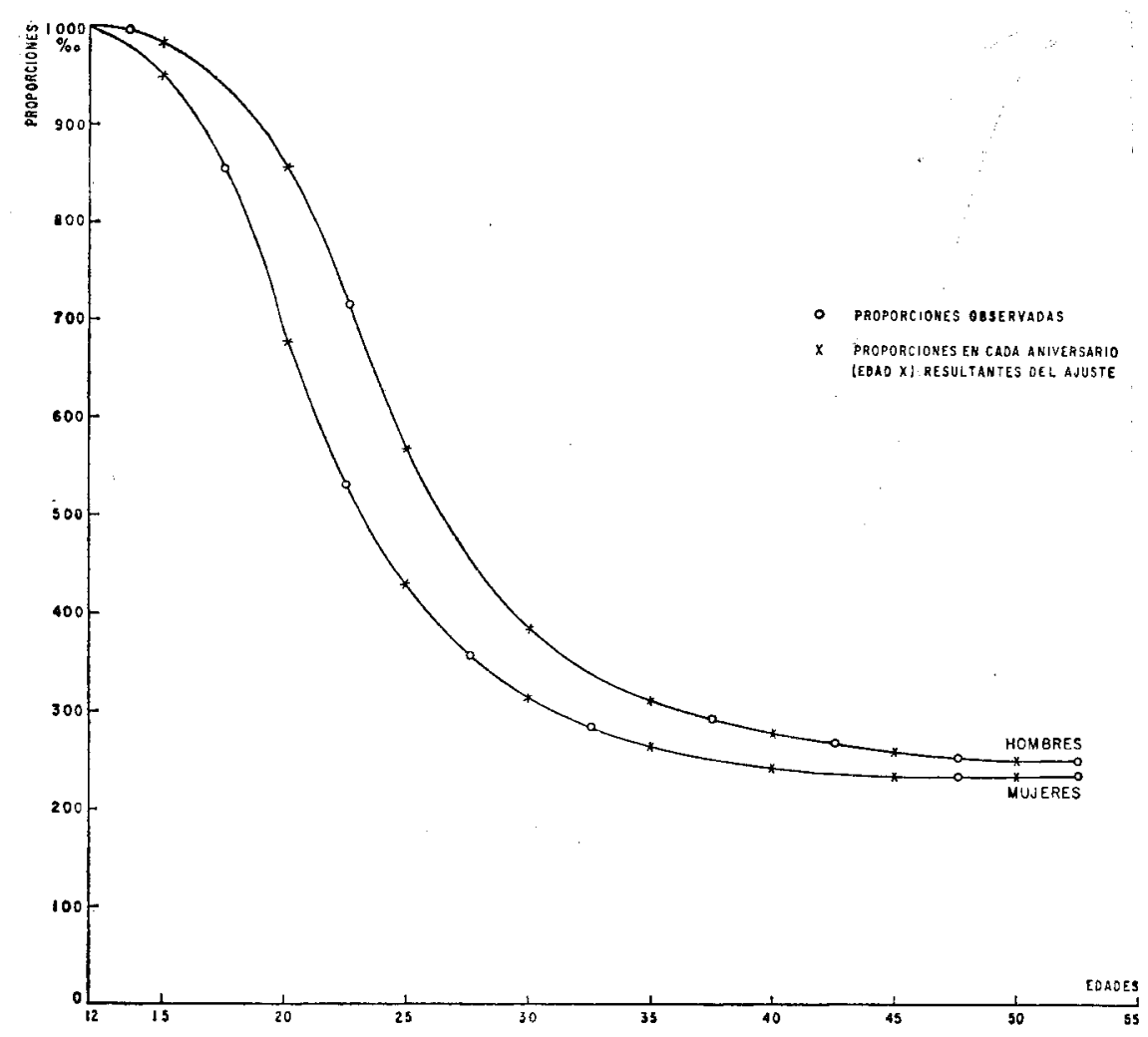




\section{Gráfica 4}

MÉxico: AJUSTE GRáfico de LAS PROPORCIONES DE LA POBlaCión DE 15 AÑOS Y MÁS (SOLTERA, EN UNIÓN LIBRE Y MATRIMONIO SÓLO RELIGIOSO). 1976 (ENCUESTA MUNDIAL DE FECUNDIDAD)

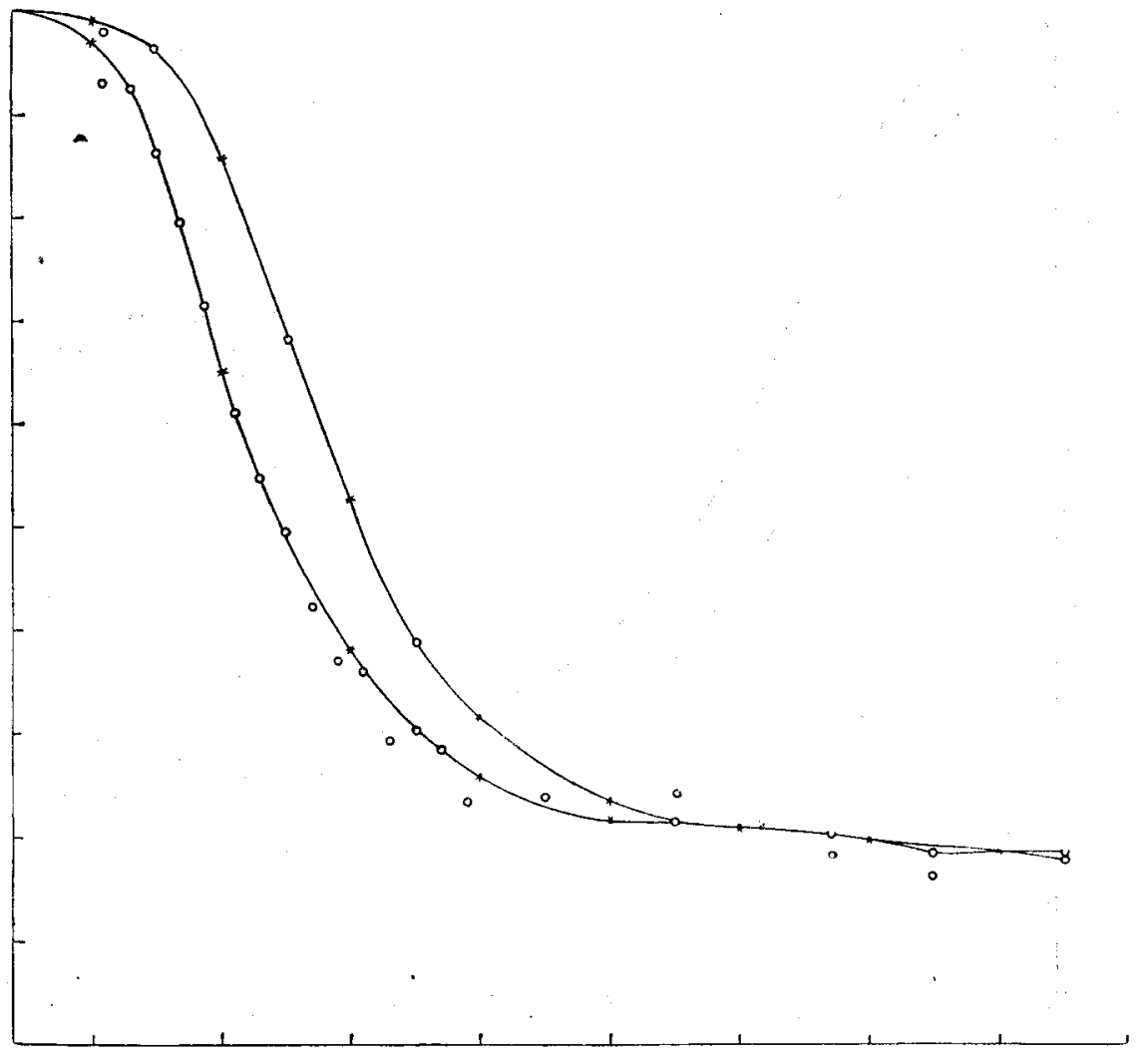


Gráfica 5

MÉxico: AJUSTE GRÁfico de LAS PROPORCínes de SOLTEROS DE 12 AÑOS Y MÁS POR GRUPOS DE EDADES QUINQUENALES. CENSO 1970

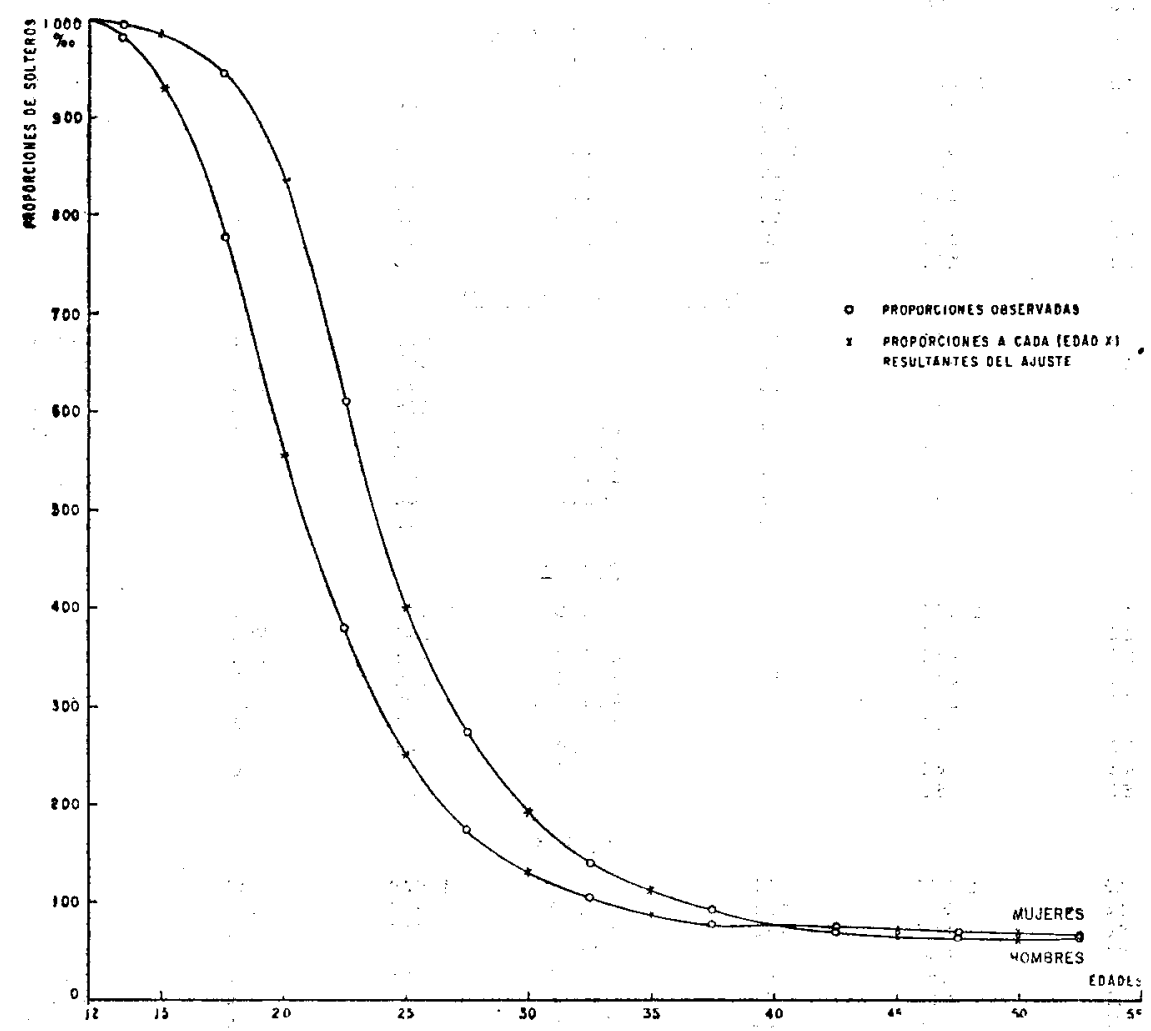


Anexo 2

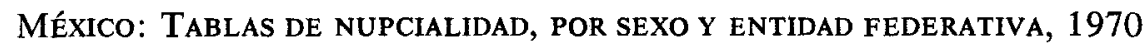

\begin{tabular}{|c|c|c|c|c|c|c|}
\hline \multirow{2}{*}{$\begin{array}{c}\text { Edad } \\
(x)\end{array}$} & \multicolumn{3}{|c|}{ Hombres } & \multicolumn{3}{|c|}{ Mujeres } \\
\hline & $\mathrm{cn}$ & ${ }^{M}, x+a$ & $\begin{array}{c}a^{n} x \\
(0 / 00)\end{array}$ & $\mathrm{cn}$ & ${ }^{M}, x+a$ & $\begin{array}{c}a^{a} x \\
(0 / 00)\end{array}$ \\
\hline \multicolumn{7}{|c|}{ Aguascailientes } \\
\hline 12 & 1000 & 15 & 15.0 & 1000 & 45 & 45.0 \\
\hline 15 & 985 & 120 & 121.8 & 955 & 335 & 350.8 \\
\hline 20 & 865 & 465 & 537.6 & 620 & 295 & 475.8 \\
\hline 25 & 400 & 210 & 525.0 & 325 & 155 & 476.9 \\
\hline 30 & 190 & 85 & 447.4 & 170 & 50 & 294.1 \\
\hline 35 & 105 & 30 & 285.7 & 120 & 20 & 166.7 \\
\hline 40 & 75 & 20 & 266.7 & 100 & 5 & 50.0 \\
\hline 45 & 55 & 0 & 0 & 95 & 0 & 0 \\
\hline 50 & 55 & - & - & 95 & - & - \\
\hline \multicolumn{7}{|c|}{ Baja CaIifornia Sur } \\
\hline 12 & 1000 & 10 & 10.0 & 1000 & 40 & 40.0 \\
\hline 15 & 990 & 60 & 80.6 & 960 & 400 & 416.7 \\
\hline 20 & 930 & 450 & 483.9 & 560 & 290 & 517.9 \\
\hline 25 & 480 & 210 & 437.5 & 270 & 135 & 500.0 \\
\hline 30 & 270 & 110 & 407.4 & 135 & 40 & 296.3 \\
\hline 35 & 160 & 20 & 187.5 & 95 & 10 & 105.3 \\
\hline 40 & 130 & 15 & 115.4 & 85 & 5 & 58.8 \\
\hline 45 & 115 & 10 & 87.0 & 80 & 0 & 0 \\
\hline 50 & 105 & - & - & 80 & - & - \\
\hline \multicolumn{7}{|c|}{ Baja Californja Norte } \\
\hline 12 & 1000 & 15 & 15.0 & 1000 & 45 & 45.0 \\
\hline 15 & 985 & 95 & 96.4 & $\quad 955$ & 365 & 382.2 \\
\hline 20 & 890 & 430 & 483.1 & 590 & 325 & 550.8 \\
\hline 25 & 460 & 225 & 489.1 & 265 & 140 & 528.3 \\
\hline 30 & 235 & 115 & 489.4 & 125 & 45 & 360.0 \\
\hline 35 & 120 & 25 & 208,3 & 80 & 15 & 187.5 \\
\hline 40 & 95 & 15 & 157.9 & 65 & 0 & 0 \\
\hline 45 & 80 & 5 & 62.5 & 65 & - & - \\
\hline 50 & 75 & - & - & 65 & - & - \\
\hline \multicolumn{7}{|c|}{ Campeche } \\
\hline 12 & 1000 & 20 & 20.0 & 1000 & 55 & 55.0 \\
\hline 15 & 980 & 130 & 132.7 & 845 & 490 & 518.5 \\
\hline 20 & $850^{\circ}$ & 535 & 629.4 & 455 & 265 & 582.4 \\
\hline 25 & 315 & 160 & 507.9 & 190 & 105 & 552.6 \\
\hline 30 & 155 & 65 & 419.4 & 85 & 35 & 411.8 \\
\hline 35 & 90 & 15 & 166.7 & 50 & 5 & 100.0 \\
\hline 40 & 75 & 15 & 200.0 & 45 & 0 & 0 \\
\hline 45 & 60 & 0 & 0 & 45 & 0 & - \\
\hline 50 & 60 & - & - & 45 & - & - \\
\hline \multicolumn{7}{|c|}{ Coahuila } \\
\hline 12 & 1000 & 20 & 20.0 & 1000 & 50 & 50.0 \\
\hline 1: & 980 & 115 & 117.3 & 950 & 420 & 442.1 \\
\hline 20 & 865 & 480 & 554.9 & 530 & 280 & 528.3 \\
\hline 25 & 385 & 190 & 493.5 & 250 & 125 & 500.0 \\
\hline 30 & 195 & 80 & 410.3 & 125 & 45 & 360.0 \\
\hline 35 & 115 & 30 & 260.9 & 80 & 20 & 250.0 \\
\hline 40 & 85 & 10 & 117.6 & 60 & 0 & 0 \\
\hline 45 & 75 & 10 & 133.3 & 60 & 0 & 0 \\
\hline 50 & 65 & - & - & 60 & - & - \\
\hline \multicolumn{7}{|c|}{ Colizne } \\
\hline 12 & 1000 & 15 & 15.0 & 1000 & 55 & 55.0 \\
\hline 15 & 985 & 80 & 81.2 & 945 & 375 & 396.8 \\
\hline 20 & 905 & 435 & 480.7 & 570 & 285 & 500.0 \\
\hline 25 & 470 & 255 & 542.6 & 285 & 145 & 508.8 \\
\hline 30 & 215 & 85 & 385.3 & 140 & 40 & 285.7 \\
\hline 35 & 130 & 35 & 269.2 & 100 & 20 & 200.0 \\
\hline 40 & 95 & 15 & 157.9 & 80 & 5 & 62.5 \\
\hline 45 & 80 & 5 & 62.5 & 75 & 0 & - \\
\hline 50 & 75 & - & - & 75 & - & $=$ \\
\hline
\end{tabular}




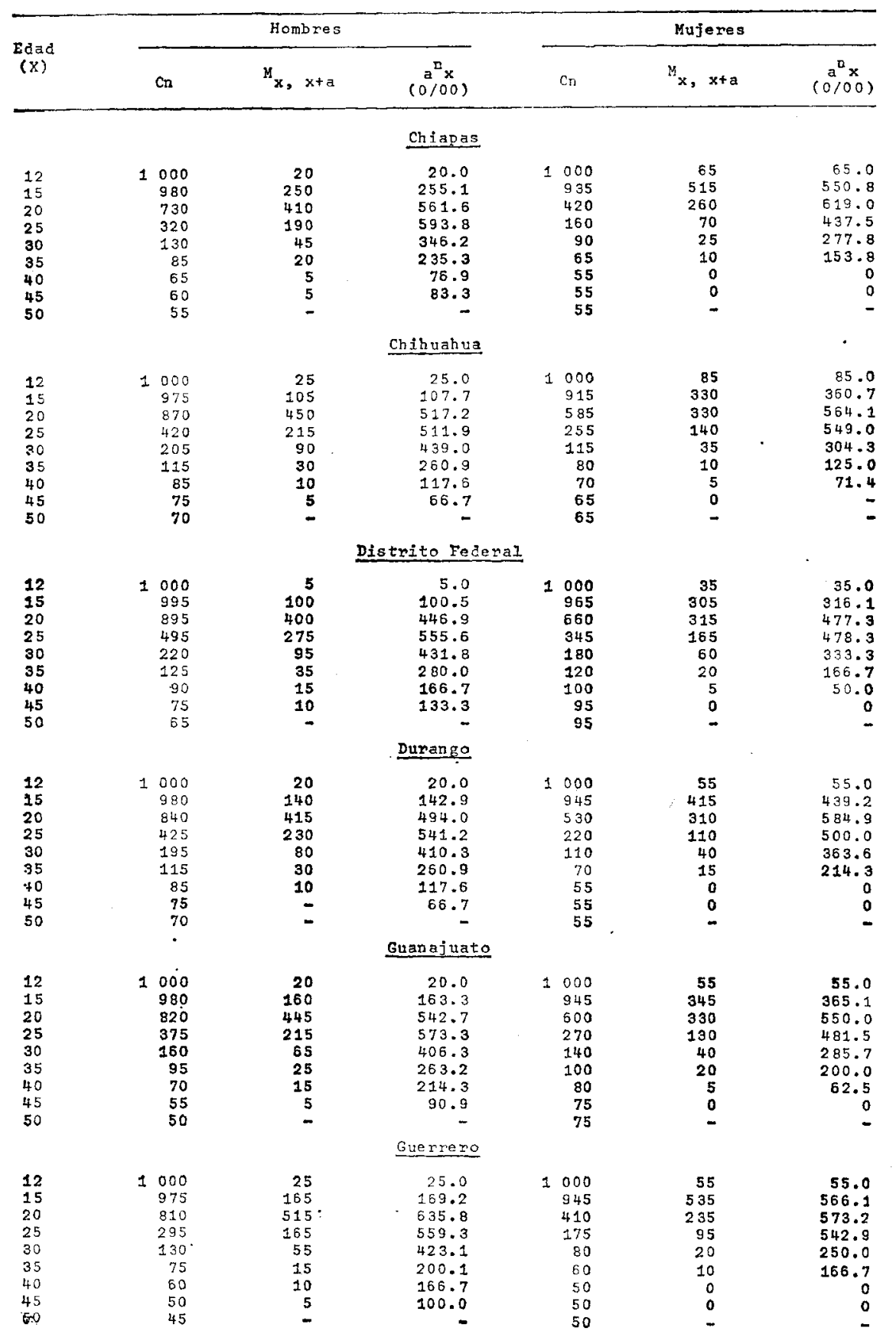




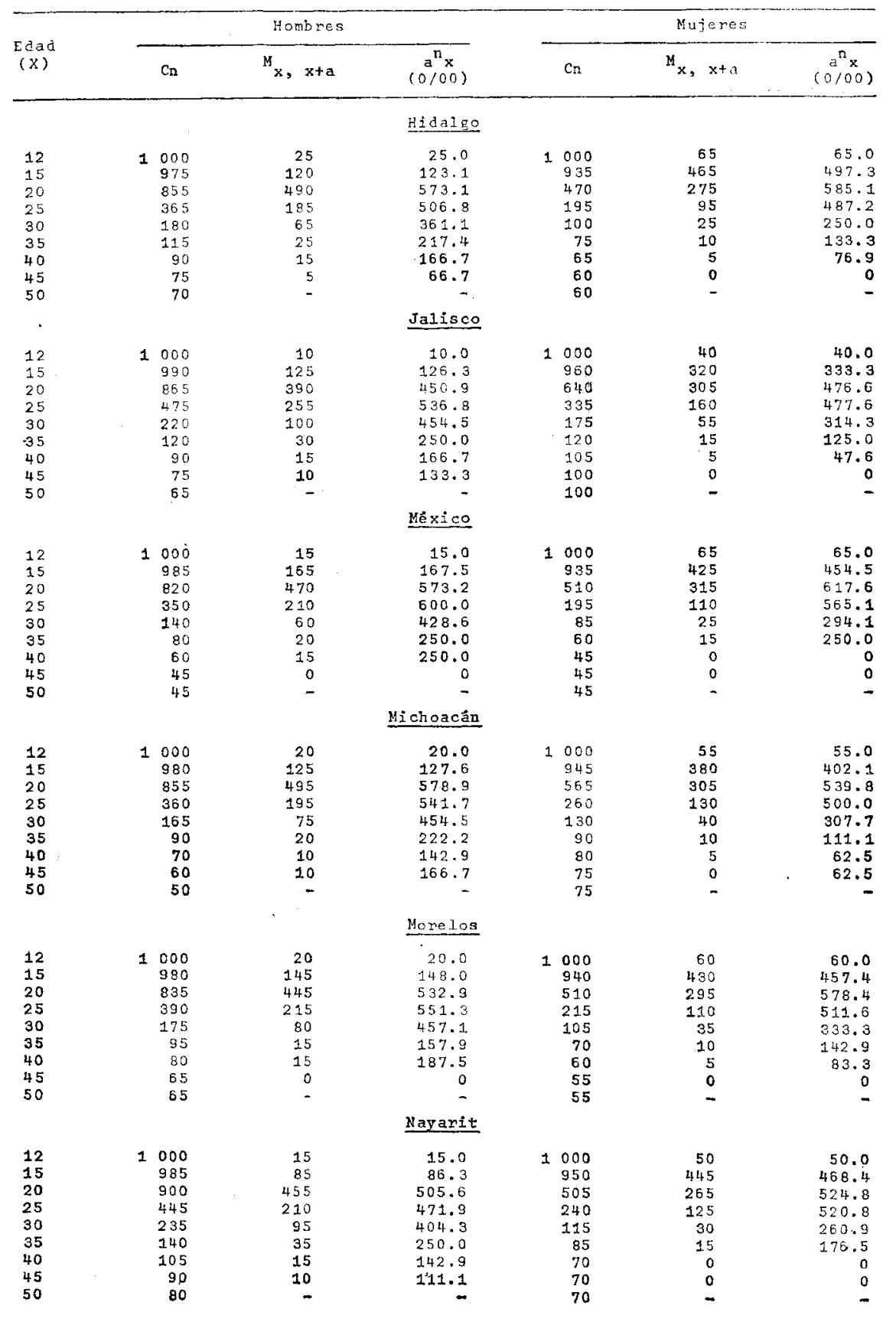




\begin{tabular}{|c|c|c|c|c|c|c|}
\hline \multirow{2}{*}{$\begin{array}{c}E \text { dad } \\
(x)\end{array}$} & \multicolumn{3}{|c|}{ Hombres } & \multicolumn{3}{|c|}{ Mujeres } \\
\hline & $\mathrm{Cn}$ & $M_{x}, x+a$ & $\begin{array}{c}a^{n} x \\
(0 / 00)\end{array}$ & Cn & ${ }^{M} x, x+a$ & $\begin{array}{c}a: x \\
(0 / 00)\end{array}$ \\
\hline \multicolumn{7}{|c|}{ Nuevo Leôn } \\
\hline 12 & 1000 & 10 & 10.0 & 1000 & .45 & 4.5 .0 \\
\hline 15 & 990 & 105 & -10.6 .1 & 955 & 325 & 340.3 \\
\hline 20 & 885 & 430 & 485.9 & 6.30 & 320 & 507.9 \\
\hline 25 & 455 & $23^{5}$ & 516.5 & 310 & 160 & 516.1 \\
\hline 30 & 220. & 105 & 477.3 & 150 & 5.5 & 366.7 \\
\hline 35 & 115 & 25 & 217.4 & 95 & 15 & 157.9 \\
\hline 40 & 90 & 15 & 166.7 & 80 & 5 & 62.5 \\
\hline 45 & 75 & 10 & 133.3 & 75 & 0 & $\therefore 0$ \\
\hline 50 & 65 & - & & 75 & - & - \\
\hline \multicolumn{7}{|c|}{ Qaxaca } \\
\hline 12 & 1000 & 25 & 25.0 & i1 000 & 60 & 60.0 \\
\hline 15 & 975 & 180 & 184.6 & 940 & 480 & 510.6 \\
\hline 20 & 795 & 435 & .547 .2 & 460 & 255 & 554.3 \\
\hline 25 & 360 & 195 & 541.7 & 205 & 95 & 463.4 \\
\hline 30 & 165 & 70 & 424.2 & 110 & 30 & 272.7 \\
\hline 35 & 95 & 30 & 315.8 & 80 & 10 & 125.0 \\
\hline 40 & 65 & 10 & .153 .8 & 70 & $\therefore 5$ & 71.4 \\
\hline 45 & 55 & 5 & 90.9 & 6.5 & 0 & 0 \\
\hline 50 & 50 & - & - & 65 & 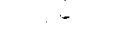 & - \\
\hline \multicolumn{7}{|c|}{ Puebla } \\
\hline 12 & 1000 & $20 \because$ & 20.0 & 100.0 & .60 & 60.0 \\
\hline 15 & 980 & 165 & 16.8 .4 & 940 & 430 & 457.4 \\
\hline 20 & 815 & 435 & 533.7 & 510 & 280 & 549.0 \\
\hline 25 & 380 & 2.15 & 565.8 & 230 & $110^{\circ}$ & 478.3 \\
\hline 30 & 165 & 65 & 393.9 & 120 & 40 & 333.3 \\
\hline 35 & 100 & 25 & 250.0 & 80 & 10 & 125.0 \\
\hline 40 & 75 & 15 & 200.0 & 70 & 5 & 71.4 \\
\hline 45 & 60 & 5 & 83.3 & 65 & 0 & $\therefore 0$ \\
\hline so & 55 & - & - & 65 & - & - \\
\hline \multicolumn{7}{|c|}{ Quenetaro } \\
\hline 12 & 1000. & 15 & 15.0 & 1000. & 50 & 50.0 \\
\hline 15 & 985 & 140 & 142.1 & 950 & 425 & 447.4 \\
\hline 20 & 84.5 & 485 & 574.0 & 525 & 295 & 561.9 \\
\hline 25 & 360 & 205 & 569.4 & 230 & 10.5 & 456.5 \\
\hline 30 & 155 & 65 & 419.4 & 125 & 35 & 280.0 \\
\hline 35 & 90 & 25 & 277.8 & 90 & 15 & 166.7 \\
\hline 40 & 65 & 15 & 230.8 & 75 & 5 & 66.7 \\
\hline 45 & 50 & 5 & 100.0 & 70 & 0 & 0 \\
\hline 50 & 45 & - & - & 70 & - & - \\
\hline \multicolumn{7}{|c|}{ Quintana Roo } \\
\hline 12 & 1000 & 25 & 25.0 & 1000 & 80 & 80.0 \\
\hline 15 & 97.5 & 210 & 215.4 & 920 & 550 & 597.8 \\
\hline 20 & 765 & 470 & 614.4 & 370 & 245 & 662.2 \\
\hline 25 & 295 & 155 & 525.4 & 125 & 6.5 & 520.0 \\
\hline 30 & 140 & 40 & 285.7 & 60 & 25 . & 416.7 \\
\hline 35 & 100 & 30 & 300,0 & 35 & 5 & 142.9 \\
\hline 40 & 70 & 15 & 214.3 & 30 & 5 & 166.7 \\
\hline 45 & 55 & 0 & 0 & 25 & 0 & $\quad 0$ \\
\hline 50 & 55 & - & - & 25 & - & - \\
\hline \multicolumn{7}{|c|}{ San Luis Potoss } \\
\hline & 100 & & & & & \\
\hline $\begin{array}{l}12 \\
15\end{array}$ & $\begin{array}{l}1000 \\
985\end{array}$ & $\begin{array}{r}15 \\
145\end{array}$ & 15.0 & 1000 & $60:$ & 60.0 \\
\hline $\begin{array}{l}23 \\
20\end{array}$ & $\begin{array}{l}980 \\
840\end{array}$ & $\begin{array}{l}145 \\
435\end{array}$ & $\begin{array}{l}147.2 \\
517.9\end{array}$ & 940 & 420 & 446.8 \\
\hline 25 & 405 & 220 & 543.2 & $\begin{array}{l}520 \\
240\end{array}$ & $\begin{array}{l}280 \\
115\end{array}$ & $\begin{array}{l}538.5 \\
479.2\end{array}$ \\
\hline 30 & 185 & 75 & $405: 4$ & 125 & 35 & 280.0 \\
\hline 35 & 110 & 30 & 272.7 & 90 & 15 & 166.7 \\
\hline 40 & 80 & 15 & 187.5 & 75 & 0 & 0 \\
\hline 45 & 65 & 5 & 76.9 & 75 & 5 & 66.7 \\
\hline 50 & 60 & - & - & 70 & - & - \\
\hline
\end{tabular}




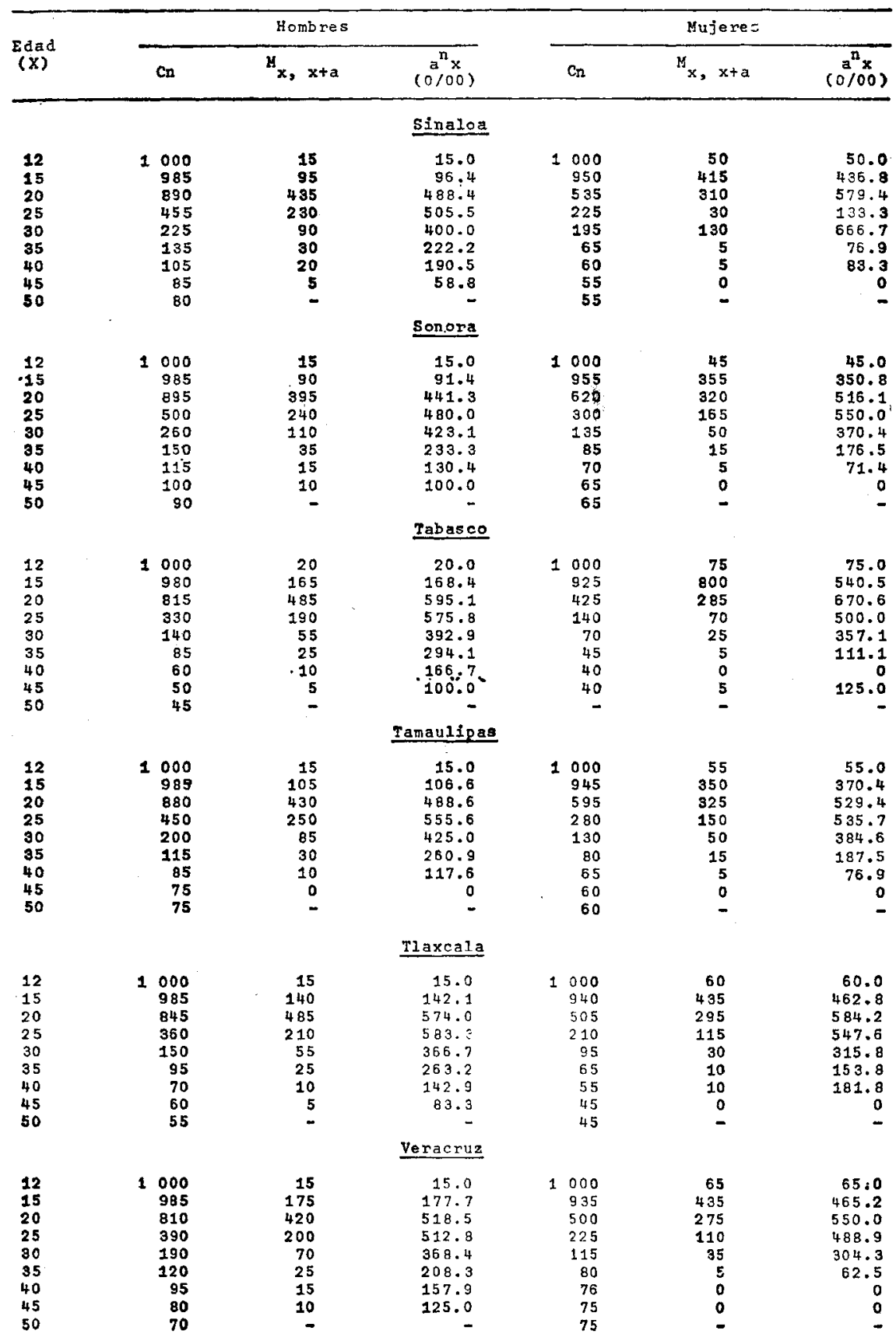




\begin{tabular}{|c|c|c|c|c|c|c|}
\hline \multirow[b]{2}{*}{$\begin{array}{l}\text { Edad } \\
(x)\end{array}$} & \multicolumn{3}{|c|}{ Hombres } & \multicolumn{3}{|c|}{ Mujeres } \\
\hline & $\mathrm{Cn}$ & $M_{x, x+a}$ & $\frac{a^{n} x}{(0 / 00)}$ & $\mathrm{c}_{\mathrm{n}}$ & $M, x+a$ & $(0 / 00)$ \\
\hline \multicolumn{7}{|c|}{ Yucatán } \\
\hline 12 & 1000 & 20 & 20.0 & 1000 & 60 & 60.0 \\
\hline 15 & 980 & 195 & 199.0 & 940 & 420 & 446.8 \\
\hline 20 & 785 & 440 & 560.5 & 520 & 285 & 548.1 \\
\hline 25 & 345 & 180 & 521.7 & 235 & 125 & 531.9 \\
\hline 30 & 165 & 60 & 363.6 & 110 & 40 & 363.6 \\
\hline 35 & 105 & 20 & 190.5 & 70 & 10 & 142.9 \\
\hline 40 & 85 & 15 & 176.5 & $60^{\circ}$ & 5 & 83.3 \\
\hline 45 & 70 & 5 & 71.4 & 55 & 0 & 0 \\
\hline 50 & 65 & - & - & 55 & - & - \\
\hline \multicolumn{7}{|c|}{ Zacatecas } \\
\hline 12 & 1000 & 20 & 20.0 & 1000 & 55 & 55.0 \\
\hline 15 & 980 & 160 & 163.3 & 945 & 405 & 428.6 \\
\hline 20 & 820 & 420 & 512.2 & 540 & 295 & 546.3 \\
\hline 25 & 400 & 210 & 525.0 & 245 & 130 & 530.6 \\
\hline 30 & 190 & 90 & 473.7 & 115 & 35 & 304.3 \\
\hline 35 & 100 & 30 & 300.0 & 80 & 10 & 125.0 \\
\hline 40 & 70 & 7 & 100.0 & 70 & 5 & 71.4 \\
\hline 45 & 63 & 5 & 79.4 & 65 & 0 & 0 \\
\hline 50 & 58 & - & - & 65 & - & - \\
\hline
\end{tabular}




\section{Anexo 3}

México: Saldos netos Migratorios, tasas netas de Migración E Índices DE MASCULINIDAD, POR ENTIDAD FEDERATIVA, 1960-1970

\begin{tabular}{|c|c|c|c|c|c|c|c|c|c|c|c|c|c|}
\hline \multirow{3}{*}{ Entidad } & & \multirow{3}{*}{8} & \multirow{3}{*}{ Sexo } & \multicolumn{4}{|c|}{ Tasa neta de migracion } & \multicolumn{3}{|c|}{ Masculinidadef } & \multicolumn{2}{|c|}{ Masculinjdadd } \\
\hline & & & & & \multirow[t]{2}{*}{$15-19$} & \multirow[t]{2}{*}{$20-24$} & \multirow[t]{2}{*}{$25-29$} & \multirow{2}{*}{ Total } & \multirow[t]{2}{*}{$15-19$} & \multirow[t]{2}{*}{$20-24$} & \multirow[t]{2}{*}{$25-29$} & \multirow{2}{*}{$\frac{H(20-24)}{H(15-19)}$} & \multirow{2}{*}{$\frac{\mathrm{m}(25-29)}{\mathrm{M}(20-24)}$} \\
\hline & & & & & & & & & & & & & \\
\hline Méxíco & 659 & 763 & 41.1 & $\stackrel{H}{M}$ & $\begin{array}{l}28.2 \\
27.0\end{array}$ & $\begin{array}{l}32.4 \\
36.3\end{array}$ & $\begin{array}{l}42.3 \\
47.7\end{array}$ & $\begin{array}{l}33.8 \\
34.2\end{array}$ & 1.00 & 0.94 & 0.96 & 0.795 & 0.810 \\
\hline Distrito Federal & 472 & 886 & 29.5 & $\stackrel{\mathrm{H}}{\mathrm{M}}$ & $\begin{array}{l}16.0 \\
23.7\end{array}$ & $\begin{array}{l}32.7 \\
26.9\end{array}$ & $\begin{array}{r}22.3 . \\
9.6\end{array}$ & $\begin{array}{l}6.1 \\
7.7\end{array}$ & 0.88 & 0.91 & 0.94 & 0.792 & 0.711 \\
\hline Wuevo León & 154 & 028 & 9.6 & : & $\begin{array}{l}21.1 \\
21.7\end{array}$ & $\begin{array}{l}23.2 \\
19.6\end{array}$ & $\begin{array}{l}15.1 \\
13.7\end{array}$ & $\begin{array}{l}13.7 \\
14.7\end{array}$ & 0.98 & 0.96 & 0.98 & 0.837 & 0.787 \\
\hline Baja California Norte & 139 & 374 & 8.7 & $\stackrel{H}{M}$ & $\begin{array}{l}15.9 \\
18.7\end{array}$ & $\begin{array}{l}20.2 \\
23.7\end{array}$ & $\begin{array}{l}24.9: \\
25.0\end{array}$ & $\begin{array}{l}16.8 \\
18.7\end{array}$ & 0.93 & 0.85 & 0.90 & 0.690 & 0.693 \\
\hline $\begin{array}{l}\text { Morelos } \\
\text {. }\end{array}$ & 45 & 574 & 2.9 & H & $\begin{array}{l}12.0 \\
10.8\end{array}$ & $\begin{array}{l}11.9 \\
12.3\end{array}$ & $\begin{array}{l}15.0 \\
15.3\end{array}$ & $\begin{array}{l}14.4 \\
14.6\end{array}$ & 1.00 & 0.93 & 0.93 & 0.742 & 0.768 \\
\hline Tamaulipas & 32 & 011 & $2 . \dot{0}$ & $-\mathrm{H}$ & $\begin{array}{l}3.3 \\
5.6\end{array}$ & $\begin{aligned}-1.2 \\
3.21\end{aligned}$ & $\begin{array}{r}-2.1 \\
1.6\end{array}$ & $\begin{array}{l}3.2 \\
3.5\end{array}$ &.- .95 & $0: 86$ & 0.90 & 0.720 & 0.718 \\
\hline Quintana Roo & 24 & 612 & 1.6 & $\stackrel{\text { H }}{M}$ & $\begin{array}{l}19.9 \\
20.3\end{array}$ & $\begin{array}{l}33.7 \\
28.0\end{array}$ & $\begin{array}{l}38.9 \\
29.9\end{array}$ & $\begin{array}{l}19.9 \\
18.0\end{array}$ & 1.02 & 1.04 & 1.08 & 0.853 & 0.836 \\
\hline Sonora & 21 & 430 & 1.3 & $\stackrel{H}{M}$ & $\begin{array}{l}3.6 \\
3.6\end{array}$ & $\begin{array}{l}2.8 \\
1.8\end{array}$ & $\begin{array}{r}1.0 \\
-0.6\end{array}$ & $\begin{array}{l}2.3 \\
1.4\end{array}$ & 0.97 & 0.91 & 0.95 & 0.725 & 0.752 \\
\hline $\sin a 10 a$ & 18 & 089 & 1.1 & H & $\begin{array}{l}8.5 \\
6.6\end{array}$ & $\begin{array}{r}3.4 \\
-1.3\end{array}$ & $\begin{array}{r}2.0 \\
-1.2\end{array}$ & $\begin{array}{l}8.2 \\
5.8\end{array}$ & 1.01 & .0 .98 & 1.01 & 0.769 & 0.794 \\
\hline colima & 14 & 710 & 0.9 & H & $\begin{array}{l}8.2 \\
4.0\end{array}$ & 2.4 & $1 \cdot \begin{array}{l}2.8^{\circ} \\
1.5\end{array}$ & $\begin{array}{l}5.7 \\
4.6\end{array}$ & 0.99 & 0.94 & 0.97 & 0.723 & 0.753 \\
\hline campeche & $1 i$ & 392 & 0.7. & $\stackrel{\mathrm{H}}{\mathrm{M}}$ & $\begin{array}{r}8.5 \\
12.0\end{array}$ & $\begin{array}{l}7.3 \\
5.7\end{array}$ & $\begin{array}{r}7.2 \\
9.3\end{array}$ & $\begin{array}{l}9.3 \\
8.5\end{array}$ & 0.95 & 0.94 & 0.93 & 0.710 & 0.755 \\
\hline Baja California sur & 9 & 894 & $0.6^{\circ}$ & $\stackrel{\dot{H}}{M}$ & $\begin{array}{l}11.6 \\
10.0\end{array}$ & $\begin{array}{r}13.9 \\
6.5\end{array}$ & $\begin{array}{r}14.4 \\
9.7\end{array}$ & $\begin{array}{l}12.7 \\
10.4\end{array}$ & 1.03 & 0.98 & 1.04 & 0.788 & 0.838 \\
\hline chisuthua & & $5: 16$ & $0: 0$ & $\cdot \stackrel{H}{M}$ & $\begin{array}{l}=2.8 \\
=3.9\end{array}$ & $\begin{array}{r}-4.9 \\
6.5\end{array}$ & $\begin{array}{l}=7.4 \\
-7.8\end{array}$ & $\begin{array}{l}6.3 \\
5.5\end{array}$ & 0.98 & 0.92 & 0.911 & 0.752 & 0.752 \\
\hline Nayarit & -5 & $240^{\circ}$ & 0.3 & . $\stackrel{\mathrm{H}}{\mathrm{M}}$ & $\begin{array}{r}1.2 \\
-7.1\end{array}$ & $\begin{array}{r}-6.6 \\
-13.4\end{array}$ & $\begin{array}{l}-8.5 \\
-10.8\end{array}$ & $\begin{array}{l}0.8 \\
2.3\end{array}$ & $i .07$ & 0.97 & 1.00 & 0.738 & 0.793 \\
\hline Tabasco. & -6 & $: 055$ & 0.4 & $\stackrel{H}{M}$ & $\begin{array}{l}4.5 \\
5.9\end{array}$ & $\begin{array}{l}2.8 \\
4.7\end{array}$ & $\begin{array}{l}6.0 \\
6.3\end{array}$ & $\begin{array}{l}7.4 \\
5.2\end{array}$ & 0.96 & 0.93 & 0.92 & 0.697 & 0.770 \\
\hline Jalisco & -8 & 329 & $0.5^{\circ}$ & $\stackrel{H}{M}$ & $\begin{array}{r}-0.8 \\
0.3\end{array}$ & $\begin{array}{l}3.5 \\
-5.2\end{array}$ & $\begin{array}{l}-10.4 \\
-10.0\end{array}$ & $\begin{array}{r}-2.9 \\
-2.4\end{array}$ & 0.97 & 0.92 & 0.93 & 0.741 & 0.696 \\
\hline
\end{tabular}




\begin{tabular}{|c|c|c|c|c|c|c|c|c|c|c|c|c|c|}
\hline Aguascalientes & -11 & 903 & 0.7 & $\begin{array}{l}H \\
M\end{array}$ & $\begin{array}{r}-0.7 \\
1.4\end{array}$ & $\begin{array}{l}-7.3 \\
-6.0\end{array}$ & $\begin{array}{r}-14.4 \\
-8.9\end{array}$ & $\begin{array}{l}-2.2 \\
-0.5\end{array}$ & 0.97 & 0.90 & 0.92 & 0.696 & 0.682 \\
\hline Vexacruz & -15 & 082 & 0.8 & $\stackrel{H}{M}$ & $\begin{array}{r}0.4 \\
-1.2\end{array}$ & $\begin{array}{l}0.2 \\
0.7\end{array}$ & $\begin{array}{l}3.2 \\
4.4\end{array}$ & $\begin{array}{l}1.6 \\
0.8\end{array}$ & 0.99 & 0.92 & 0.94 & 0.773 & 0.780 \\
\hline Queretaro & -2.3 & 862 & 1.5 & $\begin{array}{l}\mathrm{H} \\
\mathrm{M}\end{array}$ & $\begin{array}{r}-4.9 \\
-\quad 7.2\end{array}$ & $\begin{array}{l}-10.0 \\
-10.8\end{array}$ & $\begin{array}{l}-8.1 \\
-6.4\end{array}$ & $\begin{array}{r}-3.7 \\
-4.2\end{array}$ & 1.00 & 0.95 & 0.95 & 0.727 & 0.793 \\
\hline Tláxcala & -36 & 107 & 2.2 & $\stackrel{H}{H}$ & $\begin{array}{l}-15.7 \\
-27.6\end{array}$ & $\begin{array}{r}-28.5 \\
-30.2\end{array}$ & $\begin{array}{l}-26.6 \\
-18.7\end{array}$ & $\begin{array}{l}-12.8 \\
-15.0\end{array}$ & 1.09 & 0.96 & 0.92 & 0.757 & 0.769 \\
\hline Chiapas & -.37 & 867 & 2.4 & $\begin{array}{l}\mathrm{H} \\
\mathrm{M}\end{array}$ & $\begin{array}{l}-12.9 \\
-28.2\end{array}$ & $\begin{array}{r}-12.5 \\
0.6\end{array}$ & $\begin{array}{l}-0.91 \\
-16.3\end{array}$ & $\begin{array}{l}-8.4 \\
-9.0\end{array}$ & 0.96 & 0.88 & 0.92 & 0.742 & 0.780 \\
\hline Xucatân & -47 & 283 & 2.9 & $\begin{array}{l}\text { H } \\
\text { M }\end{array}$ & $\begin{array}{r}-5.1 \\
-3.5\end{array}$ & $\begin{array}{r}-9.7 \\
-9.4\end{array}$ & $\begin{array}{r}-19.9 \\
-5.6\end{array}$ & $\begin{array}{r}-6.7 \\
-5.8\end{array}$ & 0.97 & 0.93 & 0.89 & 0.752 & 0.671 \\
\hline Coahuila & -55 & 345 & $3.4^{\circ}$ & $\begin{array}{l}\mathrm{H} \\
\mathrm{M}\end{array}$ & $\begin{array}{r}-7.5 \\
-15.8\end{array}$ & $\begin{array}{l}-11.7 \\
-16.9\end{array}$ & $\begin{array}{l}-17.6 \\
-11.5\end{array}$ & $\begin{array}{l}-11.1 \\
-11.7\end{array}$ & 1.01 & 0.95 & 0.95 & 0.774 & 0.744 \\
\hline Durango & -88 & 416 & 5.5 & $\stackrel{H}{M}$ & $\begin{array}{l}-12.6 \\
-18.7\end{array}$ & $\begin{array}{l}-19.1 \\
-23.0\end{array}$ & $\begin{array}{l}-24.5 \\
-22.0\end{array}$ & $\begin{array}{l}-14 \\
-15.5\end{array}$ & 1.03 & 0.95 & 0.96 & 0.761 & 0.760 \\
\hline Guerrero & -113 & 643 & 7.1 & $\underset{M}{\mathrm{H}}$ & $\begin{array}{l}-12.2 \\
-11.6\end{array}$ & $\begin{array}{l}-21.0 \\
-12.3\end{array}$ & $\begin{array}{l}9.0 \\
1.8\end{array}$ & $\begin{array}{r}-6.4 \\
-5.1\end{array}$ & 0.98 & 0.86 & 0.88 & 0.693 & 0.772 \\
\hline Hidalgo & -121 & 383 & 7.6 & $\stackrel{H}{M}$ & $\begin{array}{l}-18.3 \\
-26.2\end{array}$ & $\begin{array}{l}-24.3 \\
-23.3\end{array}$ & $\begin{array}{l}-17.8 \\
-1.0 .8\end{array}$ & $\begin{array}{l}-14.3 \\
-15.6\end{array}$ & 1.04 & 0.93 & 0.94 & 0.755 & 0.819 \\
\hline San Luis Potos & -125 & $j 17$ & 7.9 & $\begin{array}{l}\text { H } \\
\text { M }\end{array}$ & $\begin{array}{l}-14.3 \\
-20.4\end{array}$ & $\begin{array}{l}-20.1 \\
-22.3\end{array}$ & $\begin{array}{l}-19.6 \\
-16.6\end{array}$ & $\begin{array}{l}-13.0 \\
-14.4\end{array}$ & 1.03 & 0.94 & 0.93 & 0.746 & 0.766 \\
\hline Puebla & -135 & 837 & 8.5 & H & $\begin{array}{l}-12.6 \\
-14.6\end{array}$ & $\begin{array}{l}-15.4 \\
-15.6\end{array}$ & $\begin{array}{r}-12.9 \\
2.1\end{array}$ & $\begin{array}{l}-7.7 \\
-7.5\end{array}$ & 0.99 & 0.91 & 0.92 & 0.737 & 0.766 \\
\hline Oaxaca & -156 & 855 & 9.8 & $\stackrel{H}{M}$ & $\begin{array}{l}-17.9 \\
-20.3\end{array}$ & $\begin{array}{l}-20.3 \\
-13.8\end{array}$ & $\begin{array}{l}-9.0 \\
-3.0\end{array}$ & $\begin{array}{r}-8.9 \\
-8.9\end{array}$ & 0.97 & 0.88 & 0.99 & 0.737 & 0.779 \\
\hline Guanajuato & -165 & 856 & 10.3 & $\begin{array}{l}\mathrm{H} \\
\mathrm{M}\end{array}$ & $\begin{array}{r}-7.8 \\
-10.2\end{array}$ & $\begin{array}{l}-13.7 \\
-15.8\end{array}$ & $\begin{array}{l}-15.4 \\
-15.2\end{array}$ & $\begin{array}{l}-7.3 \\
-8.5\end{array}$ & 1.00 & 0.93 & 0.94 & 0.715 & 0.735 \\
\hline Zacatecâs & -177 & 074 & 10.7 & $\begin{array}{l}\mathrm{H} \\
\mathrm{M}\end{array}$ & $\begin{array}{l}-27.1 \\
-28.6\end{array}$ & $\begin{array}{l}-36.0 \\
-36.1\end{array}$ & $\begin{array}{l}-38.0^{\circ} \\
-33.1\end{array}$ & $\begin{array}{l}-23.1 \\
-23.2\end{array}$ & 1.00 & 0.90 & 0.91 & 0.695 & 0.721 \\
\hline Michoacăn & -278 & 380 & 17.4 & $\begin{array}{l}\mathrm{H} \\
M\end{array}$ & $\begin{array}{l}-14.0 \\
-17.1\end{array}$ & $\begin{array}{l}-23.7 \\
-23.0\end{array}$ & $\begin{array}{l}-23.1 \\
-20.4\end{array}$ & $\begin{array}{l}-11.3 \\
-12.2\end{array}$ & 1.01 & 0.30 & 0.91 & 0.593 & 0.698 \\
\hline$T \circ t a I$ & 1604 & 234 & 100.0 & & & & & & & & & & \\
\hline
\end{tabular}

a Tomados de "Política demográfica regional. Objetivos y metas, 1978-1982", conapo, 1978. Cálculo de los saldos migratorios a partir de la respuesta censal a la pregunta sobre residencia anterior.

Tomados de "Tasas de migración neta según grupos de edad por entidad federativa, México, 1930-1970", El Colegio de México, (inédito), cálculo de los saldos migratorios a través del método de sobrevivéncia censal. a Tomas del IX Censo Genal de Población, 1970, resumen genal, D.c.e., Mécico, 1972. 